NBER WORKING PAPER SERIES

\title{
CREDIT RATIONING AND PASS-THROUGH IN SUPPLY CHAINS: THEORY AND EVIDENCE FROM BANGLADESH
}

\author{
M. Shahe Emran \\ Dilip Mookherjee \\ Forhad Shilpi \\ M. Helal Uddin \\ Working Paper 26615 \\ http://www.nber.org/papers/w26615 \\ NATIONAL BUREAU OF ECONOMIC RESEARCH \\ 1050 Massachusetts Avenue \\ Cambridge, MA 02138 \\ January 2020
}

\begin{abstract}
An earlier version of the paper was circulated under the title "Do Consumers Benefit from Supply Chain Intermediaries? Evidence from a Policy Experiment in Edible Oils Market in Bangladesh". We are grateful to the Editors and two anonymous referees for perceptive comments on an earlier draft that substantially improved the paper. Wally Mullin, Chris Woodruff, Raymond Guiteras, Andrew Foster, Sabyasachi Das, Marcel Fafchamps, Sebastian Bustos, Nidhiya Menon, Wahiduddin Mahmud, Fahad Khalil, Will Martin provided helpful comments. Thanks to Rubaiya Emran for help with the graphs. We thank participants at development workshops at Cornell and Georgetown Universities, and at the AEA Annual Conference 2016 at San Francisco, NEUDC 2014 at Boston University, GCER Conference 2015 at Georgetown University and IGC conference at Dhaka for comments on earlier drafts. The project received funds from KCP Trust Fund (World Bank) and IGC Bangladesh country program. The views expressed herein are those of the authors and do not necessarily reflect the views of the National Bureau of Economic Research.

NBER working papers are circulated for discussion and comment purposes. They have not been peer-reviewed or been subject to the review by the NBER Board of Directors that accompanies official NBER publications.

(C) 2020 by M. Shahe Emran, Dilip Mookherjee, Forhad Shilpi, and M. Helal Uddin. All rights reserved. Short sections of text, not to exceed two paragraphs, may be quoted without explicit permission provided that full credit, including $\odot$ notice, is given to the source.
\end{abstract}


Credit Rationing and Pass-Through in Supply Chains: Theory and Evidence from Bangladesh M. Shahe Emran, Dilip Mookherjee, Forhad Shilpi, and M. Helal Uddin NBER Working Paper No. 26615

January 2020

JEL No. L13,O12,Q13

ABSTRACT
We extend standard models of price pass-through in an imperfectly competitive
incorporate rationing of trade credit. Credit rationing reverses predictions concern
material import prices on pass-through to wholesale prices, and effects
intermediaries. To test these we study the effects of a policy in Bangladesh's edible
during 2011-12 banning a layer of financing intermediaries. Evidence from a differen
estimation rejects the standard model. We find that the regulatory effort to reduce
financing intermediaries ended up raising consumer prices by restricting acce
downstream traders.
$\begin{array}{ll}\text { M. Shahe Emran } & \text { Forhad Shilpi } \\ \text { Initiative for Policy Dialogue } & \text { Development Research Group } \\ \text { Columbia University } & \text { World Bank } \\ \text { New York, NY } & \text { Washington, DC } \\ \text { USA } & \text { USA } \\ \text { shahe.emran@gmail.com } & \text { fshilpi@worldbank.org } \\ \text { Dilip Mookherjee } & \text { M. Helal Uddin } \\ \text { Department of Economics } & \text { Department of Economics } \\ \text { Boston University } & \text { Dhaka University } \\ \text { 270 Bay State Road } & \text { Dhaka } \\ \text { Boston, MA 02215 } & \text { Bangladesh } \\ \text { and NBER } & \text { umhelal@gmail.com } \\ \text { dilipm@bu.edu } & \end{array}$

A data appendix is available at http://www.nber.org/data-appendix/w26615 


\section{Introduction}

The role of market power of trade intermediaries in earning high margins that unduly raise consumer prices has frequently been a matter of public concern. Such concerns motivate arguments for regulations, often taking extreme forms such as outright bans on some intermediary layers, and, in some cases, more extreme penalties:

"For my part, I wish every one of them (speculators) had his devilish head shot off". (Abraham Lincoln, quoted in Carpenter (1866, p. 84))

"For as long as we fail to treat speculators the way they deserve - with a bullet in the head - we will not get anywhere at all". ((Vladimir Lenin, 1964, p. 311).)

In 1958 private trades in onions futures were banned in Chicago; distrust of private traders led to the establishment of marketing boards in many developing countries in 1950s and 1960s. However, disappointing results with the marketing boards prompted agricultural market liberalization starting from the late 1970s. The lack of trust in middlemen traders in commodity markets nevertheless remains widespread and deeply ingrained; the price spiral in international commodity markets in 2007-2008 brought their role back into focus. In 2011, the Bangladesh government banned a layer of intermediaries called Delivery Order Traders (DOTs) in edible oils distribution trade, out of a concern that their market power was primarily responsible for the rising consumer prices since 2008. However, there is relatively little systematic evidence on the effects of such policy actions.

In this paper we describe shortcomings of the standard models of pass-through used widely in the literature to understand the role of marketing intermediaries and the effects of policy actions. In particular, we argue that they pay insufficient attention to the financing role of intermediaries and related contractual frictions. The standard model of double marginalization of rents with constant marginal costs (e.g., Atkin-Donaldson (2015), based on a Bulow-Pfleiderer (1983) specification of downstream consumer demand) generates a linear pass-through equa-

tion, where pass-through rates (of changes in the trader's unit cost to downstream prices) are 
independent of crude oil import price levels or the trader's unit distribution costs, and decreasing in concentration at each layer of the supply chain. This model therefore predicts that the pass-though of oil price shocks to the downstream consumer price should have risen after the reform, owing to the de-concentration induced by elimination of an intermediate layer. As crude import prices were falling after the reform was implemented, a higher pass-through rate should have resulted in faster decline in downstream price of edible oil. However, as our empirical analysis shows, downstream prices rose instead.

If the model were modified to incorporate the role of the intermediaries in providing trade credit to downstream traders, banning the intermediaries would cause financing costs of the traders to rise. This would tend to raise the downstream price, offsetting to some extent the effect of de-concentration. However, if unit costs of traders continue to be invariant to quantity traded — as would be the case without credit rationing — the model continues to predict that (i) passthrough rates are independent of crude import price or trader's distribution costs. This in turn implies that (ii) pass-through should be higher after the reform owing to the induced de-concentration. Both of these predictions turn out to be rejected in our empirical analysis.

We show, however, that when we incorporate financial contracting frictions between intermediaries and traders resulting in quantitative rationing of trade credit access of the latter, neither of these predictions continue to hold. When traders' credit constraints bind, the extended model predicts instead that (iii) the pass-through rate falls if crude import prices rise or credit constraints shrink, and (iv) if the reform caused trader credit limits to contract sufficiently, this could offset the de-concentration effect and cause the pass-through rate to fall (and the downstream price to rise) overall.

The contrasting predictions of the standard model and our extended model are tested using daily wholesale and retail palm oil price data in Bangladesh spanning 2008-2013, a period which includes the drastic policy reform banning financing intermediaries (DOTs) from the market. A straightforward approach would be to compare the passthrough and the price level in the post-reform period with those in the pre-reform period. However, estimates of the effects of the reform from this before-after approach are likely to be biased because we do not have data 
on trader distribution costs such as storage and transport which could be correlated with the crude import price or the timing of the reform. We develop a difference-in-difference (DiD) strategy and compare changes in oil prices with the changes in wheat and lentil prices, whose raw material is also imported and incur similar transport and storage costs. We take advantage of the data from the pre-reform period and test the validity of the parallel trends assumption using a series of placebo reforms. The evidence does not reject the null hypothesis of parallel trends at the 10 percent level for any of the placebo reforms.

Before estimating the price effects of the reform, we use data from the pre-reform period to test the competing predictions (i) and (iii) of the two models respectively concerning variation of pass-through rates with respect to oil import price shocks. Pass-through was significantly smaller when the import price was above the median, thereby rejecting prediction (i) in favor of prediction (iii). ${ }^{2}$ Moreover, consistent with the simple version of our credit rationing model, the pass-through rate depended only on the level of the oil import price, but not whether they were rising or falling over time.

Our subsequent analysis then focuses on the effects of the reform on pass-through rates and price levels for edible oil, relative to those for wheat and lentils (where the reform did not apply). Given the evidence in favor of prediction (iii) in the pre-reform period, we compare post-reform prices with those in the pre-reform period where the average level of oil prices were comparable to those in the pre-reform period. The DiD estimates show that the policy reform reduced the pass-through rate and increased the price level in edible oil relative to wheat or lentils. Hence we reject prediction (ii) of the standard model, in favor of (iv) from the credit rationing model. Our estimates imply a 9.5 percent higher wholesale prices of palm oil (significant at the 1 percent level) during the first 9 months after the reform was implemented.

These conclusions are robust to alternative specifications of oil import lags and different data samples (including the announcement period in the sample, including two rather than one year data from the pre-reform period, or including data from both high and low crude

\footnotetext{
${ }^{2}$ This also enables us to reject an extension of the standard model where unit costs of traders are rising in quantity, owing to capacity constraints. As explained in Section 5, such a model predicts a higher pass-through when import prices are higher.
} 
import prices). We also check the results using wheat and lentil separately as the comparison commodity. At the same time, a "placebo treatment" DiD for the effects of the reform on wheat as the pretend treatment and lentil as the comparison commodity yields no significant effects.

We discuss supplementary evidence consistent with the credit rationing hypothesis, based on case-studies, as well as data on aggregate crude import volumes which contracted sharply (at a time when import prices were falling). The lower passthrough and higher prices following the DOT ban capture the effects of higher interest rates on bank loans in the post-reform period in addition to the tighter credit constraints lowering the volume of oil trade. The wholesale traders faced substantially higher marginal costs which lowered the passthrough rate, and the tightening of credit constraints effectively lowered the price elasticity of the derived demand functions faced by upstream refiners, resulting in higher refiner markups. These disruptions overwhelmed whatever reductions in market concentration resulted from the elimination of the DOTs from the market. It also helps explain why the reform was reversed, following pressure from palm oil refiners who were struggling to offload their accumulating inventories. We also explain why search cost related explanations are likely to be relevant in explaining the effects of the Bangladesh policy reform.

The rest of the paper is structured as follows. Section 2 discusses related literature. Section 3 describes the institutional setting of the palm oil supply chain in Bangladesh and the nature of the reform. Section 4 develops the theoretical model, followed by extensions of the model in section 5. A discussion of estimation strategy is in Section 6. Section 7 then describes the data and presents the empirical results. Section 8 discusses supplementary evidence and possible competing explanations, while Section 9 concludes.

\section{Related Literature}

The evidence and analysis presented in this paper are most closely related to a large literature on imperfect pass-through of international prices and exchange rate variations to domestic pro- 
ducer and consumer prices (e.g., Goldberg and Hellerstein (2008), Nakamura (2008), Nakamura and Zerom (2010), Gopinath et al. (2010), Berman et al. (2012), Bonnet et al. (2013), and recent surveys by Burstein and Gopinath (2013), Campa and Goldberg (2008)). Weyl and Fabinger (2013) present a unifying framework for incidence with imperfect competition. This framework has been fruitfully utilized in the context of developing countries by Atkin and Donaldson (2015). Analogous to our approach, they use the Bulow-Pfleiderer (1983) specification of demand to derive a constant pass-through rate that depends only on market concentration and demand curvature. They use this to recover trade costs from spatial price differences. As in the standard model, intermediaries in their model play a role in trade and physical distribution rather than financing, and contract frictions such as credit constraints have no role.

The literature in development economics has paid more attention to contracting frictions, resulting from adverse selection, moral hazard and enforcement problems. Models of interlinked trade-credit relationships have appeared in Braverman and Stiglitz (1984) and Bardhan (1984, 1989). Burkart and Ellingsen (2004) show that relative illiquidity of commodities implies that it is easier to provide trade credit compared to a pure credit contract. This argument is relevant for our application, because a DO is considerably less liquid than money: it may not be easy for a wholesaler to find a DO buyer willing to pay cash without offering significant discounts. More important, the DOTs rely on accumulated information about the wholesalers to minimize adverse selection and moral hazard, and default information is shared quickly among the DOTs in a market, similar to multilateral punishment scheme a la Greif (1993). Information and monitoring advantages have been identified as important factors for supplier credit (see, for example, Smith (1987)).

Recent empirical work in developing countries on intermediaries and commodity supply chains have examined pass-through of international or retail prices to farm-gate prices when trade intermediaries operate as middlemen between farmers and retail or foreign buyers (Casaburi et al. (2013), Minten and Kyle (1999)). Many of these focus on search frictions to explain pass-through patterns, while Mitra et. al. (2018) consider implications of asymmetric price in- 
formation. ${ }^{3}$ Macchiavello and Morjara (2016) analyze the effects of competition in procurement of inputs on relational contracts between farmers and coffee mills in Rwanda. Casaburi and Reed (2017) focus on the supply chain from farmers to traders to wholesalers in Sierra Leone cocoa market. Price subsidies paid to randomly chosen middlemen did not result in higher output prices paid to farmers, but instead to higher advance payments. The "effective price" paid to the farmers thus is not directly observable in the data and require indirect valuation of the advance payments. They report significant pass-through rate (0.92) of wholesale prices to the effective prices paid to farmers, suggesting that markets were reasonably competitive and middlemen did not exert much monopsony power. Their paper complements ours by providing direct evidence of the role of middlemen in providing trade credit, besides assessing the extent of their market power. Our paper goes further by evaluating the overall impact of the presence of financing middlemen (aggregating the effects of their market power and trade credit provision), using a natural experiment that affected an entire country, and using data on actual prices.

Although there has been a renewed interest in the domestic food markets in developing countries in response to price shocks in the international market, most studies (e.g., Ivanic et al. (2012)) estimate the effects of higher international prices on domestic prices (pass-through) in reduced form regressions without a theoretical model; their focus is usually on the implications of higher consumer prices for poverty. These studies do not attempt to understand the role of intermediaries or the effects of efforts to regulate their activities.

\footnotetext{
${ }^{3}$ Rust and Hall (2003) consider a model of interactions between middlemen (dealers/brokers) and market makers. The prices offered by middlemen can be discovered through costly search process, but market makers post publicly observable bid and ask prices. They characterize the conditions under which the entry by a market maker into a middlemen-only initial equilibrium is Pareto-improving. Middlemen do not provide credit in their model.
} 


\section{The Palm Oil Marketing Chain in Bangladesh and the 2011 Reform}

\subsection{Pre-Reform}

We start with a brief description of the Bangladesh palm oil marketing chain before the DOT ban in 2011; a more detailed discussion is provided in Uddin and Taslim (2010). As the reform was effectively suspended by mid-2012, the current structure of the supply chain resembles the way it was organized prior to the reform. The chain consists of four layers: refiners, delivery order traders (DOTs), wholesalers and retailers. The refining segment is highly concentrated with only nine refiners, some of them have considerable excess capacity. The refiners import crude palm oil from Malaysia and Indonesia and then refine it. While wholesalers can pick up refined oil directly from the refiners upon paying cash, such direct transactions between the wholesalers and the refiners are limited. The wholesalers mostly furnish a delivery order (DO) to take oil delivery, a paper document representing an entitlement to a defined quantity of refined oil from the refinery. DOs are purchased by DOTs from refiners, sometimes immediately after the crude oil is imported, and sold later to the wholesalers on credit or cash. The wholesalers buying DOs on credit repay in the next period after selling the oil to retailers. The DOTs thus offer a bundled oil and credit contract when selling DOs on credit to wholesalers.

There are approximately 300 DOTs divided between two principal cities Dhaka and Chittagong, forming an intermediate layer between refiners and over 7000 wholesalers. Wholesalers mostly prefer to purchase through a DOT rather than directly from a refiner primarily because of the credit implicitly provided by a DOT. Estimates from a trader survey that we conducted in the two main markets in Dhaka and Chittagong in 2013 shows that about 32 percent of quantity transacted between the DOTs and wholesalers was on credit without collateral, based on long-term relationships.

The DOTs buy DOs for oil deliverable by the refiner after a stipulated period of time (usually 2 weeks). It is important to note that DOTs never take physical delivery of the oil: they are pure financial intermediaries. This is helpful for our empirical analysis, as the banning 
of DOTs cannot affect the distribution costs such as storage and transport costs directly. The DOT layer interacts vertically with the refiners upstream and the wholesalers downstream. In effect, they purchase refined oil from the refiners and re-sell it after a time lag to wholesalers.

There are also some horizontal transactions among DOTs, representing arbitrage, speculation or purchase by smaller DOTs from the large DOTs. The horizontal transactions among the DOTs have evolved into something like an embryonic commodity exchange in Moulovibazar in Dhaka and Khatunganj in Chittagong where speculators operate with the help of brokers, primarily during upswings in the international market. ${ }^{4}$ Our post-reform data period however coincided with a downswing in the international market when activities in the secondary (horizontal) DOT market were almost nonexistent. An implication of this coincidental downturn in the international market is that our analysis cannot draw any inferences regarding the potential role of speculative activities by the DOTs (and other market agents) observed during the upturn in the market. Since one of the goals of the reform declared by the government was to curb harmful speculation, we cannot shed any light on whether such policies would help in attaining this policy goal. In our analysis, we focus on the pricing implications of market power and credit rationing across vertical layers in a static framework, and thus abstract from price dynamics, risk, or heterogeneity across traders within any layer.

\subsection{The Reform}

The policy reform focused on the DO layer of the market. The law banning DO (Delivery Order) transactions and instituting SO (Sales Order) dealers in its place (i.e., Essential Commodities Marketing and Distributor Appointment Order 2011) was passed on March 23, 2011. 90 days were allowed to implement the policy change, implying that the directive implementing the law came into effect on June 21, 2011.

\footnotetext{
${ }^{4}$ It is difficult to characterize the DO layer neatly; it is like a nascent futures market, missing some features of a standard futures market. For example, unlike a futures market, there is no settlement at the end of the day, and payment is made at the time of the DO contract, not at the delivery date. The DO contracts have built in some flexibility similar to an option contract; for example, the stipulated delivery date is almost never enforced.
} 
It was argued by the government and popular media that in the DO system a few big players exert disproportionate market power and manipulate the market by strategically buying, holding and selling DOs. This layer was sought to be entirely eliminated in the new system, in which wholesalers were expected to purchase oil directly from refiners. In the new ('supply order' (SO)) system, new dealers were appointed for each "marketing area" (for example, upazila or municipality) selected by the refiners, and a dealer was allowed to buy oil upto a limit "commensurate with" the size of the market. In total, 7388 dealers for edible oil were appointed by different refiners. While wholesalers were principally expected to become the new SO dealers, it would have been difficult to prevent previous DOTs from acquiring dealerships. This was the logic underlying the quantity restrictions on the amount of oil that could be purchased by a dealer, so that even if an ex-DOT became a dealer he would not be able to engage in bulk purchases and sales of SOs. Combined with the large number of SO dealerships created, the policy effectively reduced market concentration within the supply chain.

However, the elimination of DOTs also meant disappearance of an important source of credit for wholesalers. Refiners were unable to step in to fill this gap because they lacked the information accumulated by the DOTs over decades. Accordingly, the wholesalers had to turn to banks for credit to finance dealership deposits and purchase of SOs for oil from the refiners. Many faced difficulty in obtaining sufficient credit. This made it difficult for the refiners to set up a new network of SO dealers. City Group, one of the largest refiners which accounted for nearly half of all new dealerships created, was forced to waive the required security deposits. A related problem was the lack of storage among wholesalers, who were expected to pick up refined oil earlier in the new system in the absence of the DOTs.

As a result of these problems, the wholesale-traders-turned-SO-dealers were increasingly unable to pay for the required oil, and refiners began to accumulate stocks beyond their desired level of inventory. This prompted the refiners to look for alternative distribution channels; eventually they went back to some of the large DOTs to return into the business and undermine the new system. Approximately six months after the reform went into effect, the DOTs started to circumvent the quantity restrictions imposed, with the government taking little initiative to 
enforce these restrictions (presumably owing to pressure from refiners). This passivity set into motion forces that pushed back the marketing system towards the old DO system; within a year or so the old system was back in play.

\section{Theory}

We model a vertical chain with three layers: refiners, DOTs and wholesale traders (depicted below by $i \in\{r, d, t\})$ specializing in refining, financing, and distribution, respectively. Although the edible oil supply chain also includes retailers, we ignore them as the focus is on the effects of the elimination of the DOTs on wholesale prices. ${ }^{5}$ So we assume that wholesalers sell directly to final consumers. ${ }^{6}$

The sequence of moves follows a classic hierarchical Cournot model: refiners move first and sell to DOTs. DOTs then sell to the traders, and finally, traders sell to the consumers. At each stage/layer, sellers make quantity decisions, incorporating their effects on the selling price. All sellers at each stage are symmetric, and move simultaneously. Buyers take the price as given. Given total quantity decided by sellers, an auction sets the price to clear the market. The sequence of moves and strategies at each stage is described below. We solve for a subgame perfect Nash equilibrium of this game, using backward induction.

There are two dates $T=0,1$. Crude oil is imported by refiners at $T=0$. Refining takes one period, and refined oil becomes available at $T=1$. Normalize units so that one unit of crude generates one unit of refined oil. At $T=1$, refined oil is picked up by traders from the refineries, transported to retail markets where they are sold to the consumers. Transport and other distribution costs are incurred by the traders at $T=1$.

At $T=0$, the sequence of moves is as follows.

(i) Refiners decide how much crude oil to import (at an exogenously given price $P_{m}$ ) and

\footnotetext{
${ }^{5}$ In the empirical analysis, we will also report estimates of the effects of the policy reform on retail prices.

${ }^{6}$ Owing to its recursive structure, it is easy to extend the model to incorporate an additional fourth layer of retailers who sell to final consumers. Indeed, the model with a retail layer reduces to the one developed below when there are sufficiently many retailers that the market power at that layer is negligible.
} 
sell DO's (entitlements to one unit of refined oil at $T=1$ ) to the DOTs. The imported crude is refined at a unit cost of $C_{r}$.

(ii) Each DOT decides how many DOs to buy at the prevailing market price $P_{r}$ which they take as given. Since the DOTs pay for these DO's at $T=0$, they effectively finance the purchases of the refiners. $P_{r}$ is determined, by equating refiners' aggregate supply of DO's to the total demand by the DOTs. DOTs do not incur any physical costs of handling the oil $\left(C_{d}=0\right)$; they only incur financing costs. Each DOT has unlimited access to credit at a fixed interest rate $i_{d}$. We assume that the financing costs incurred by the DOTs are lower than the financing costs of refiners and the banks. ${ }^{7}$

(iii) DO's are resold (on credit) by DOTs to the traders, in the form of bundled oil-pluscredit contracts. Traders do not pay the DOTs anything for the DOs at $T=0$. The price of this contract $P_{d}$ is for the bundle of oil entitlement combined with credit which the trader promises to pay the DOT at $T=1$ (after selling the refined oil to the consumers). We assume that the cost of borrowing from the bank (denoted as $i_{b}$ ) is high enough so that the traders do not find it profitable to buy directly from the refiners (paying cash). ${ }^{8}$

At stage (iii), traders decide how many DO's to buy, taking $P_{d}$ as given. The market clearing price $P_{d}$ is thus determined along with the allocation of DO's among traders.

(iv) Next, period $T=1$ arrives. Traders use their DO's to pick up refined oil, incur unit distribution cost $C_{t}$ and sell it to consumers at price $P_{t}$. Consumers take $P_{t}$ as given and decide how much to buy. The inverse market demand function takes the Bulow-Pfleiderer (1983) form:

$$
P_{t}=\alpha-\eta Q^{\delta}
$$

where $Q$ denotes the total quantity sold by traders to the consumers, and $\alpha, \eta, \delta>0 .{ }^{9}$ To avoid market shutdown, we assume that $\alpha$ is large enough relative to the sum of import, refining

\footnotetext{
${ }^{7}$ For further discussion, see Section 5 below.

${ }^{8}$ Section 5 explains in detail the justification for this assumption.

${ }^{9}$ An alternative to the Bulow-Pfleiderer demand specification is the constant elasticity demand, widely used in the theoretical literature. A constant elasticity demand function, however, implies a zero intercept in the passthrough equation. The evidence rejects the null hypothesis of a zero intercept at the 5 percent significance level
} 
finance and distribution costs:

$$
\alpha>\frac{\left(P_{m}+C_{r}\right)\left(1+i_{d}\right)}{\left(1-\frac{1}{N_{r}}\right)\left(1-\frac{1}{N_{d}}\right)}+C_{t}
$$

(v) Each trader decides whether to pay back $P_{d}$ to the DOT from whom DO's were acquired. If they fail to pay back all the purchased DOs, the DOTs impose a fixed default penalty $R_{d} \cdot{ }^{10}$

The payoffs are as follows. Refiner $j$ 's payoff (denominated at $T=0$ taka) is

$$
\Pi_{j}=\left[P_{r}-P_{m}-C_{r}\right] q_{j}
$$

where $q_{j}$ denotes the number of DO's sold by refiner $j$. DOT $k$ 's payoff (denominated at $T=0$ taka) is

$$
\Pi_{k}=\left[\frac{P_{d}}{1+i_{d}}-P_{r}\right] q_{k}
$$

upon selling $q_{k}$ DO's on credit to traders, assuming they are all repaid (which will be the case on the equilibrium path). Trader $t$ 's payoff (denominated at $T=1$ taka, since all financial receipts and payments by traders are undertaken at $T=1$ ) is

$$
\Pi_{t}=\left[P_{t}-P_{d}-C_{t}\right] q_{t}
$$

upon buying $q_{t}$ DO's on credit, selling the associated refined oil and repaying all DO's.

Traders decide on repayment as follows. If they do not repay all of their DOs, they incur the default penalty $R_{d}$. Hence if they default on a single DO, it amounts to defaulting on all of them. Relative to the payoff (5), they gain $P_{d} q_{t}$ while incurring the penalty $R_{d}$. Hence it is in all of the pass-through regressions reported in this paper. We assume $\delta>0$ given the fact that passthrough rate falls between 0 and 1 .

${ }^{10}$ It is easy to extend the model to settings where sanctions are endogenous, e.g., in a dynamic setting where sanctions involve cutting off access to credit and the oil market in future. DOTs could engage in such collective punishments as in Kandori (1992) or Greif (1993): all DOTs could refuse to sell DOs or lend to any wholesaler who defaults on a loan with any DOT. If prices are stationary, the cost of these sanctions imposed on defaulters would depend on prices, which will alter the expression for credit ceilings derived below. This complicates the analysis without affecting the results qualitatively. 
optimal to not default if

$$
P_{d} q_{t} \leq R_{d}
$$

which translates to a borrowing constraint

$$
q_{t} \leq \frac{R_{d}}{P_{d}}
$$

The quantity constraint above thus refers to the total credit a trader can get from the DOTs without violating the incentive constraint. ${ }^{11}$ We assume that the market agent responsible for auctioning off DOs to traders checks that each trader respects this borrowing constraint. This ensures prevention of market breakdown, and simplifies the analysis. Imposing this incentive compatibility constraint then makes stage (v) of the game redundant. Hence we impose constraint (7) at stage (iii), and dispense with stage (v).

Observe that the borrowing constraint is akin to a capacity constraint, with the exception that the capacity limit depends on the price $P_{d}$ which is endogenously determined. We return to this below in Section 5.3.

\subsection{Pass-Through When Credit Constraints Do Not Bind}

We first consider the equilibrium without any borrowing constraint; this corresponds to the case where default penalties $R_{d}$ are large enough (we derive the appropriate bound below). This is the standard case usually studied in existing literature (eg., Atkin and Donaldson (2016)).

Working backwards, we start by deriving the Cournot equilibrium among the traders at stage (iii), given the price of DOs $P_{d}$ charged by the DOTs. With conjectured output $q$ for each of the other $\left(N_{t}-1\right)$ traders, each trader selects $q_{t}$ to maximize

$$
\left[P_{t}\left(\left(N_{t}-1\right) q+q_{t}\right)-P_{d}-C_{t}\right] q_{t}
$$

\footnotetext{
${ }^{11}$ This assumes that the DOTs share information about loans and default which seems plausible from our own survey work in this market. The market is geographically very concentrated within a small area in Dhaka and also in Chittagong, and information sharing among DOTs is widely observed.
} 
and the resulting symmetric equilibrium satisfies

$$
\left[N_{t} q_{t}^{*}\right]^{\delta}=\frac{\alpha-P_{d}-C_{t}}{\eta\left(1+\frac{\delta}{N_{t}}\right)}
$$

Using the market-clearing condition $N_{t} q_{t}^{*}=\sum_{k} q_{k}$, this generates the inverse demand function in the stage (ii) Cournot game among the DOTs:

$$
P_{d}=\alpha-C_{t}-\eta\left(1+\frac{\delta}{N_{t}}\right)\left[\sum_{k} q_{k}\right]^{\delta}
$$

In a symmetric equilibrium at refiner price $P_{r}, q_{d}=q_{d}^{*}$ maximizes the payoff of the DOT $d$ :

$$
\left[\frac{P_{d}\left(\left(N_{d}-1\right) q_{d}^{*}+q_{d}\right)}{1+i_{d}}-P_{r}\right] q_{d}
$$

implying

$$
\left[N_{d} q_{d}^{*}\right]^{\delta}=\frac{\alpha-P_{r}\left(1+i_{d}\right)-C_{t}}{\eta\left(1+\frac{\delta}{N_{d}}\right)\left(1+\frac{\delta}{N_{t}}\right)}
$$

Finally, we solve for the stage (i) game among the refiners, given the inverse demand function generated by (12) and market-clearing:

$$
P_{r}=\frac{1}{\left(1+i_{d}\right)}\left[\alpha-C_{t}-\eta\left(1+\frac{\delta}{N_{d}}\right)\left(1+\frac{\delta}{N_{t}}\right)\left(\sum_{r} q_{r}\right)^{\delta}\right]
$$

In a symmetric equilibrium, each refiner selects $q_{r}=q_{r}^{*}$ to maximize

$$
\left[P_{r}\left(\left(N_{r}-1\right) q_{r}^{*}+q_{r}\right)-P_{m}-C_{r}\right] q_{r}
$$

which implies the industry output satisfies

$$
\left[Q^{*}\right]^{\delta} \equiv\left[N_{r} q_{r}^{*}\right]^{\delta}=\frac{\alpha-\left(P_{m}+C_{r}\right)\left(1+i_{d}\right)-C_{t}}{\eta\left(1+\frac{\delta}{N_{r}}\right)\left(1+\frac{\delta}{N_{d}}\right)\left(1+\frac{\delta}{N_{t}}\right)}
$$


and hence the consumer price equals

$$
\begin{aligned}
P_{t}^{*}= & \alpha\left[1-\left(\frac{N_{r}}{\delta+N_{r}}\right)\left(\frac{N_{d}}{\delta+N_{d}}\right)\left(\frac{N_{t}}{\delta+N_{t}}\right)\right] \\
& +\left(\frac{N_{r}}{\delta+N_{r}}\right)\left(\frac{N_{d}}{\delta+N_{d}}\right)\left(\frac{N_{t}}{\delta+N_{t}}\right)\left[C_{t}+\left(P_{m}+C_{r}\right)\left(1+i_{d}\right)\right]
\end{aligned}
$$

So we obtain the hierarchical extension of the linear pass-through equation in Atkin-Donaldson (2016). This predicts a pass-through rate $\left(1+i_{d}\right)\left(\frac{N_{r}}{\delta+N_{r}}\right)\left(\frac{N_{d}}{\delta+N_{d}}\right)\left(\frac{N_{t}}{\delta+N_{t}}\right)$ of the import price to the consumer price that depends on market concentration at each layer relative to the demand parameter $\delta$ and the cost of funds faced by the DOTs. ${ }^{12}$ Observe that this equation is linear in costs, and the pass-through rate does not depend on the oil import price $P_{m}$. Reducing concentration at any layer will raise the pass-through rate.

The credit constraint will not bind in this equilibrium if the default penalty $R_{d}$ exceeds the total amount borrowed by each trader:

$$
P_{d}^{*} q_{t}^{*} \leq R_{d}
$$

where

$$
P_{d}^{*}=\left(\alpha-C_{t}\right)\left[1-\left(\frac{N_{r}}{\delta+N_{r}}\right)\left(\frac{N_{d}}{\delta+N_{d}}\right)\right]+\left(1+i_{d}\right)\left(P_{m}+C_{r}\right)\left(\frac{N_{r}}{\delta+N_{r}}\right)\left(\frac{N_{d}}{\delta+N_{d}}\right)
$$

and

$$
q_{t}^{*}=\frac{Q^{*}}{N_{t}}
$$

where industry output $Q^{*}$ is given by (15).

\footnotetext{
${ }^{12}$ Passthrough in the standard model in the literature does not depend on the interest rate as there are no financing intermediaries. In the absence of the financing role, the passthrough thus remains constant in the face of changing macroeconomic conditions (given the market structure). In so far as the cost of funds of the financing intermediaries are affected by macroeconomic conditions, our model predicts changes in the passthrough rate.
} 


\subsection{Effects of the Reform when Credit Constraints do not Bind}

The policy reform banning the DOTs can be captured in the above model as elimination of the DOT layer $\left(N_{d}\right.$ goes to $\left.\infty\right) .{ }^{13}$ The reform raises the financing costs, as the traders have to borrow from the banks in the post-reform period instead of the DOTs; they are subject to a lower borrowing limit $\left(R_{b}\right.$ rather than $\left.R_{d}\right)$ and a higher interest rate $\left(i_{b}\right.$ rather than $\left.i_{d}\right){ }^{14}$

The passthrough rate in the post-reform period is given by $\left(1+i_{b}\right)\left(\frac{N_{r}}{\delta+N_{r}}\right)\left(\frac{N_{t}}{\delta+N_{t}}\right)$. Assuming credit constraints never bind, even after the reform (i.e., $R_{b}$ is large enough), the model thus predicts that the reform should raise the pass-through rate for two reasons: the de-concentration resulting from elimination of the DO layer, and the rise in the interest cost of traders $\left(i_{b}\right.$ rather than $i_{d}$ ). The effect on the consumer price level is ambiguous, as the price-reducing effect of eliminating the DOT mark-up is counteracted by price-raising effect of higher costs of borrowing, and the net effect can go either way. ${ }^{15}$

\subsection{Passthrough with Binding Credit Constraints}

When default sanctions $R_{d}, R_{b}$ are low enough, the credit constraint binds both before and after the reform. We solve for the corresponding symmetric subgame perfect equilibrium where the borrowing constraint holds for each trader. This means that the symmetric Cournot equilibrium at stage (iii) given $P_{d}$ is characterized by

$$
q_{t}=\frac{R_{d}}{P_{d}}
$$

\footnotetext{
${ }^{13}$ Increasing the number of DOTs $N_{d}$ has qualitatively similar effects.

${ }^{14}$ It could be argued that the former DOTs who became SO dealers after the reform could extend (pure) credit to the traders, but their ability to impose default sanctions by the threat of exclusion from trading in the oil market would no longer be available. Hence $R_{d}$ would fall substantially. Moreover market power of the DOTs in the market for loans would result in charging a higher interest rate than $i_{d}$ their cost of capital. So the effect would be qualitatively similar to borrowing from banks at a higher interest rate.

${ }^{15}$ As noted by a referee, the fact that the traders can buy directly from refiners paying cash imposes an upper bound on the margins that can be enjoyed by the DOTs in the pre-reform equilibrium. This, however, does not imply that the consumer prices must be higher after the reform, since the net effect would depend on the strength of the competition effect relative to the credit rationing and higher bank interest effects. If the former dominates, the consumer price could be lower after the reform.
} 
which generates the inverse demand function for the DOTs at stage (ii):

$$
P_{d}=\frac{N_{t} R_{d}}{\sum_{k} q_{k}}
$$

The demand function facing the DOTs now exhibits unit elasticity, with its position determined by the borrowing limits, i.e., the default penalties that can be levied on each trader by the DOTs. As trader credit constraints bind, their unit distribution costs $C_{d}$ no longer play a role.

The implicit assumption in the above formulation is that the traders do not borrow from the banks in the pre-reform period even when they are quantity rationed. This is plausible when the financing advantage offered by DOTs over banks (difference between credit limits $\left(R_{d}-R_{b}\right)$, and interest charged $\left.\left(i_{b}-i_{d}\right)\right)$ is large enough. Section 5 provides a detailed discussion of this assumption, and its plausibility in the Bangladesh context.

Cournot competition among DOTs then yields the following symmetric equilibrium: given DO purchase price $P_{r}$ (charged by the refiners), each DOT selects $q_{d}$ to maximize (at $T=1$ taka:)

$$
\left[\frac{N_{t} R_{d}}{\left[\left(N_{d}-1\right) q+q_{d}\right]\left(1+i_{d}\right)}-P_{r}\right] q_{d}
$$

so each DOT must choose

$$
q_{d}=\frac{N_{t} R_{d}}{\left(1+i_{d}\right) P_{r} N_{d}}\left[1-\frac{1}{N_{d}}\right]
$$

implying the DOT equilibrium price is

$$
P_{d}=\left(1+i_{d}\right) P_{r}\left[1-\frac{1}{N_{d}}\right]^{-1}
$$

i.e, a constant markup $\left[1-\frac{1}{N_{d}}\right]^{-1}$ over DOTs cost (including the financing cost). This is because of the unit elasticity of the demand function (21) facing the DOTs.

At stage (i) this implies the following inverse demand function for the refiners:

$$
P_{r}=\frac{N_{t} R_{d}\left(1-\frac{1}{N_{d}}\right)}{\left(1+i_{d}\right) \sum_{r} q_{r}}
$$


Observe that the demand function facing refiners also exhibits unit price elasticity, with the level depending on the borrowing limits on traders located two layers below in the supply chain. Hence the bottlenecks created by borrowing constraints on traders cascades up the supply chain, even though agents at the upper layers are not themselves credit constrained. Intuitively this is because the upper layer agents cannot bypass the traders and sell to consumers directly.

The payoff function of the representative refiner (in $T=1$ taka) in a symmetric equilibrium is:

$$
\left[\frac{N_{t} R_{d}\left(1-\frac{1}{N_{d}}\right)}{\left[\left(N_{r}-1\right) q+q_{r}\right]\left(1+i_{d}\right)}-\left(P_{m}+C_{r}\right)\right] q_{r}
$$

This equilibrium generates industry output

$$
N_{r} q_{r}^{* *}=\frac{N_{t} R_{d}\left(1-\frac{1}{N_{d}}\right)\left(1-\frac{1}{N_{r}}\right)}{\left(P_{m}+C_{r}\right)\left(1+i_{d}\right)}
$$

Refiners price DO's at a constant markup over cost:

$$
P_{r}^{* *}=\left(P_{m}+C_{r}\right)\left(1+i_{d}\right)\left(1-\frac{1}{N_{r}}\right)^{-1}
$$

implying (via (24) a price charged by the DOTs:

$$
P_{d}^{* *}=\left(1+i_{d}\right)^{2}\left(P_{m}+C_{r}\right)\left(1-\frac{1}{N_{r}}\right)^{-1}\left(1-\frac{1}{N_{d}}\right)^{-1}
$$

Hence both the refiners' and the DOTs' pricing is linear with a constant markup over cost. The binding borrowing constraints faced by the traders then determines the total output sold to the consumers, and the nonlinearity of the consumer demand function implies that the consumer price ends up being nonlinear in import and refining costs:

$$
P_{t}^{* *}=\alpha-\eta\left[\frac{N_{t} R_{d}}{\left(P_{m}+C_{r}\right)\left(1+i_{d}\right)}\left(1-\frac{1}{N_{d}}\right)\left(1-\frac{1}{N_{r}}\right)\right]^{\delta}
$$


This pass-through rate now depends on the import price:

$$
\frac{\partial P_{t}^{* *}}{\partial P_{m}}=\eta \delta\left[\frac{N_{t} R_{d}}{\left(1+i_{d}\right)}\left(1-\frac{1}{N_{d}}\right)\left(1-\frac{1}{N_{r}}\right)\right]^{\delta}\left(P_{m}+C_{r}\right)^{-(1+\delta)} .
$$

In particular, it is (a) falling in $P_{m}, C_{r}, i_{d}$, and (b) rising in credit limit $R_{d}$ and de-concentration of upper layers $N_{d}, N_{r}$.

The nonlinearity of the pass-through equation arises essentially due to the linearity of pricing of DOs in the oil import price $P_{m}$ (equation (29)), combined with the non-linearity of the consumer demand equation. If refiners costs rise owing to an increase in the oil import price, the DOT price rises by the same proportion. Since traders credit constraints bind, this implies that quantity of oil sold must fall by the same proportion. If the prior output level was smaller, the actual change in output delivered to consumers and hence the change in consumer price will also be lower. The more 'depressed' the industry to start with, the less it will contract, and the lower will the pass through rate be. This is also why a decline in credit limits for traders (resulting from elimination of the DO layer) causes the pass-through rate to fall, by depressing industry output.

Observe that while the pass-through rate depends on the level of the oil price, it does not depend on whether prices are falling or rising. This is another prediction that we shall test. ${ }^{16}$ It owes to the static nature of the model. Extending it to a dynamic context, the same prediction holds if default penalties are exogenous and stationary. If part of the sanctions on defaulting traders includes exclusion from future trading (i.e., dealers refuse to sell DOs in any future date to a trader that defaults), it includes the payoff consequences of such future exclusion. If import price shocks are i.i.d. (as in the Rotemberg-Saloner (1986) model), the default penalty would be stationary. Even otherwise it will be approximately true if oil prices follow a stationary process and traders discount future profit at a sufficiently low rate.

\footnotetext{
${ }^{16}$ Peltzman (2000) did not find evidence of asymmetry in passthrough for a third of the cases.
} 


\subsection{Predicted Effects of the Reform When Credit Constraints Bind}

The reform forces the traders to switch to borrowing from banks, and the banks impose a stricter borrowing limit besides charging a higher interest rate. In the post-reform period, there are no DOTs, which is equivalent to setting $N_{d}=\infty$. The traders borrow from banks, so $\left(R_{d}, i_{d}\right)$ would be replaced by $\left(R_{b}, i_{b}\right)$. The former effect (i.e., the elimination of the double marginalization due to DOT market power) would lower the downstream price, but the latter (increased financing cost) would raise it. The net effect can go either way, depending on which one is stronger to start with. For instance if $N_{d}$ was already quite large in the pre-reform period, the competition effect would be negligible and the financing effect could dominate. Alternatively, the competition effect could be large if $N_{d}$ was low in the pre-reform period, while the financing cost effect could be small $\left(\left(R_{b}, i_{b}\right)\right.$ could be close to $\left.\left.R_{d}, i_{d}\right)\right)$.

In similar vein, the effect on pass-through is also ambiguous: as (31) shows the competition effect and financing effect move it analogously in opposite directions. If the financing effect dominates, the price level rises and pass-through falls; otherwise the opposite happens.

However, the model does make one prediction regarding the effect of the reform: passthrough falls if and only if the price level rises. To see this, use (30) and (31) to obtain the following expression for the pass-through rate

$$
\frac{\partial P_{t}^{* *}}{\partial P_{m}}=\delta \frac{\alpha-P_{t}^{* *}}{P_{m}+C_{r}}
$$

\subsection{Relation to Model with Capacity Constraints without Credit Rationing}

How does the model with binding credit constraints relate to an extension of the standard model with capacity constraints but without credit rationing? In the latter, unit costs are not constant: they rise with the quantity of oil traded. The extreme version of such a model would have unit costs constant upto some capacity limit $\bar{q}$ on quantity; the cost associated with any higher quantity is infinite. Alternatively, unit costs could be rising smoothly with 
quantity. Rising unit costs would lower passthrough: e.g., in the extreme version of the model passthrough would be zero if the capacity limit is binding; otherwise it will be the same as in the standard model. Whether capacity constraints will bind, would depend on the price of oil. They would not bind if $q^{*} \equiv \frac{Q^{*}}{n}$ is smaller than the capacity limit $\bar{q}$, where $Q^{*}$ is given by expression (15). Given all the other parameters and costs, the capacity constraint will bind when the import price of crude oil falls below a threshold defined by the level of $P_{m}$ where the unconstrained per trader output $q^{*}$ equals the capacity limit. Hence the passthrough will be as predicted by the standard model if the price of oil is high (above the threshold), and zero otherwise.

Binding capacity constraints are similar to binding credit constraints insofar as they lower passthrough over some range of prices. However, observe that the two models differ in the exact manner in which passthrough depends on the oil import price. The passthrough rate is decreasing in the price of oil in the credit rationing model, but increasing in the price of oil in the capacity constrained model. ${ }^{17}$ They also make different predictions regarding the effects of the reform. As explained above, the credit rationing model predicts the passthrough falls if the price level rises, while the capacity constraint model predicts the opposite (owing to de-concentration and capacity constraints which are less likely to bind if $P_{m}$ is higher). Nevertheless, one way to think about credit rationing is that they impose a limit on the quantity for any trader; in this sense there is a conceptual similarity between credit constraints and capacity constraints. The relevant distinction is between different sources of capacity limit: credit rationing versus technology, as the two generate very different predictions about how the limit varies with the price.

\footnotetext{
${ }^{17}$ This is true even when unit costs rise smoothly in quantity. For instance, consider the outcome with a single layer of $N_{t}$ identical traders with unit distribution costs $C_{t}=d_{0}+d_{1} q$ with $d_{0}, d_{1}>0$ and DO price $P_{d}$ which is increasing in $P_{m}$. Then the Cournot equilibrium price $P_{t}$ satisfies $P_{t}=\alpha \frac{N_{t}}{N_{t}+\delta}+\frac{N_{t}}{N_{t}+\delta}\left[P_{d}+d_{0}+d_{1} q\right]+$ $\frac{d_{1}}{N_{t}+\delta}\left[\frac{\alpha-P_{t}}{\eta}\right]^{\frac{1}{\delta}}$, with passthrough $\frac{\partial P_{t}}{\partial P_{d}}=\frac{N_{t}}{N_{t}+\delta}\left[1+\frac{d_{1}}{\delta\left(N_{t}+\delta\right)}\left(\frac{\alpha-P_{t}}{\eta}\right)^{\frac{1}{\delta}-1}\right]^{-1}$. Capacity constraints are represented by the parameter $d_{1}$, and it is evident that passthrough is falling in $d_{1}$. And given the natural restriction that $\delta \in(0,1)$ (needed for demand elasticity to exceed unity when quantity of output exceeds unity), it follows that passthrough is rising in $P_{d}$ (hence also in $P_{m}$ ).
} 


\section{Extensions: Alternative Financing and Trading Op- tions for the Traders}

The preceding analysis is based on the assumption that the DOTs enjoy a comparative advantage in providing credit to the traders (lower interest rate and higher credit limit). In Bangladesh, the DOT's advantage over banks in financing derives from two sources. First, they can impose stronger default penalties, involving sanctions not available to banks (e.g., social sanctions, exclusion from oil trading opportunities in the future, forced seizure of assets, threats of violence etc). ${ }^{18}$ Second, the DOTs have access to loanable funds at a lower interest cost compared to banks (see the discussion in Taslim and Uddin (2010)), and have lower administrative and overhead costs. Among other factors, black money generated by tax evasion is likely to be an important source of DOT finance which cannot be deposited in banks to earn interest income.

\subsection{Traders and Bank Financing}

We now argue that under plausible parameter values, the preceding results continue to hold when we augment the financing and trading options available to the traders. First, consider the consequences of allowing the traders to purchase DOs in cash at $T=0$ from a DOT, financing this with a bank loan. Suppose we are in the hierarchical Cournot equilibrium studied in the previous section, with an equilibrium bundled price of $P_{d}^{* *}$. Then there is no scope for a trader to switch to buying any DO from a DOT in cash instead of credit. The trader would need to pay a cash price $P_{c}$ of at least $\frac{P_{d}^{* *}}{1+i_{d}}$ to ensure that the DOT is at least as well off compared with the trade credit transaction, and repay the bank $P_{c}\left(1+i_{b}\right)$. The latter is at least $P_{d}^{* *} \frac{1+i_{b}}{1+i_{d}}$, which is bigger than $P_{d}^{* *}$.

Next, consider a trader buying a DO directly from a refiner on cash at the equilibrium price $P_{r}^{* *}$, and finance this with a bank loan. This would be not be profitable if the following

\footnotetext{
${ }^{18}$ Moreover, sanctions can be imposed speedily, without going through the complex and cumbersome procedures involving bureaucratic sanctions and judicial constraints that banks have to respect.
} 
inequality holds:

$$
1+i_{b}>\frac{P_{t}^{* *}-C_{t}}{P_{r}^{* *}}-\left(\frac{R_{d}}{R_{b}}\right) \frac{P_{t}^{* *}-P_{d}^{* *}-C_{t}}{P_{d}^{* *}}
$$

Another possibility is that instead of substituting for trade credit, the trader supplements it with additional DO purchases in cash directly from the refiners by borrowing from banks. This requires paying refiners a cash price of $P_{r}^{* *}$, and repaying the bank $P_{r}^{* *}\left(1+i_{b}\right)$. The trader would not benefit from this deviation if the equilibrium consumer price $P_{t}^{* *}$ is smaller than $P_{r}^{* *}\left(1+i_{b}\right)$, i.e.,

$$
1+i_{b}>\frac{P_{t}^{* *}}{P_{r}^{* *}}
$$

Hence the equilibrium derived above continues to prevail if the interest cost of borrowing from banks is high enough so that it outweighs the benefits from avoiding the DOT markups. Note that inequality (34) is a sufficient condition for inequality (33) to hold. Using data from a 2013 survey of oil traders in Bangladesh that we conducted (Emran et al. (2015)), we can check whether inequality $(34)$ is satisfied. The ratio of wholesale price $\left(P_{t}^{* *}\right)$ to refiner price $\left(P_{r}^{* *}\right)$ is 1.097 , while the estimate for $1+i_{b}$ is 1.18 as the average bank interest rate paid by the traders is 18 percent. ${ }^{19}$ Thus, inequality (34) is satisfied in 2013 data for wholesale traders.

\subsection{Extension of the Model, with both Credit Constrained and Un- constrained Traders}

We now extend the model in a different direction, where some traders are credit constrained, and others are not. Suppose there are $N_{t u}$ unconstrained traders, and $N_{t c}$ constrained traders. The two categories of traders (subscript ' $u$ ' for unconstrained, and 'c' for constrained) differ with respect to their ability to commit to repaying credit-based transactions to the DOTs, with respective default penalties $R_{u d}, R_{u b}$ and $R_{c d}, R_{c b}$ where the subscripts 'd' and 'b' refer to credit from the DOTs and the banks respectively. So $R_{u d}, R_{u b}$ are large enough that the borrowing

\footnotetext{
${ }^{19}$ The 18 percent is based on the interest rates reported by the traders. The average interest rates on short-term bank loans reported by Bangladesh Bank is 13 percent in the post-reform period implying that $1+i_{b}=1.13$.
} 
constraints of the unconstrained traders never bind, while $R_{c d}, R_{c b}$ are substantially smaller so these represent their respective credit limits with the DOTs and the banks respectively. As before, $R_{c d}>R_{c b}$ and $i_{d}<i_{b}$.

There are thus two markets for sale of DOs by the DOTs to the traders: one in cash, and the other bundled with credit. Each DOT decides how much to sell in each of these two markets. The cash price $P_{d \$}$ is paid at period $T=0$, while the credit price $P_{d}$ is paid at $T=1$.

We claim that every sub-game perfect equilibrium of this model must be characterized by $P_{d \$}\left(1+i_{d}\right)=P_{d}$, i.e., an implicit interest rate on trade credit of $i_{d}$. The proof is as follows. If there exists an equilibrium where $P_{d \$}\left(1+i_{d}\right)<P_{d}$, the demand for cash purchases must be positive, as the unconstrained traders would strictly prefer to buy in cash. However, the DOTs would not want to supply any DOs on cash, as they strictly prefer to sell on credit. Conversely, when $P_{d \$}\left(1+i_{d}\right)>P_{d}$ both types of the traders strictly prefer to buy on credit. ${ }^{20}$ But dealers now prefer to sell only in cash, so the cash-based market cannot clear.

Next observe that every subgame perfect equilibrium is the outcome equivalent to the one in which all DOs are sold to traders on credit. This is because the DOTs and the unconstrained traders are indifferent between cash and credit, while the constrained traders strictly prefer to buy on credit (using a similar argument to the one in the previous paragraph). Hence, without loss of generality, the model reduces to one in which all DOs are sold by DOTs on credit. As $N_{t u}$ approaches zero while $N_{t c}$ is fixed, the equilibrium outcomes of the model will approach the symmetric model in the previous section where credit constraints are binding for all traders. And conversely, if $N_{t c}$ approaches zero while $N_{t u}$ is fixed, they will approach the one where they are all not binding. In general if both types of traders co-exist, a hybrid equilibrium will emerge, for which it is difficult to obtain closed-form solutions.

If traders are able to buy directly from refiners, and borrow from multiple sources, condition (34) ensures that in the case where the number of unconstrained (resp constrained) traders approaches zero, there is an equilibrium approaching one described in the previous section,

\footnotetext{
${ }^{20}$ For the unconstrained traders this is obvious; for the constrained traders buying in cash involves borrowing from banks and paying a higher interest rate, while subject to a lower credit limit, so is strictly dominated by the option of buying on credit from dealers.
} 
where traders only purchase on credit from the DOTs.

\section{Empirical Strategy}

We utilize daily data on crude palm import price and domestic wholesale price to estimate the pass-through equation and how it changed following the reform. The alternative theoretical models not only provide contrasting predictions about the effects of the reform, they also deliver testable predictions that can be tested with the data from the pre-reform period. An implication of the credit rationing model is that passthrough is lower when the import price is high, in contrast to a constant passthrough in the standard model. ${ }^{21}$ Moreover, both models are static, so they do not predict any asymmetry in passthrough, i.e., it does not depend on whether the import price is rising or falling over time. We start by testing these predictions using data from the pre-reform period.

In order to test the standard model, we would ideally estimate the following equation

$$
P_{\tau}^{l}=\gamma_{l}+\beta_{l} P_{\tau m}+\beta_{l} C_{\tau}+\epsilon_{\tau}
$$

analogous to equations (16), where $l=b, a$ refers to the regime (before and after the reform respectively), $\tau$ denotes the date, the dependent variable $P_{\tau}^{l}$ is the wholesale price during regime $j$, the regressor $P_{\tau m}$ is the crude palm import price, and $C_{\tau}$ denotes the sum of refining and distribution costs. The pass-through $\beta_{l}$ equals the product of competition variables $\frac{N_{i}}{N_{i}+\delta}$ across various stages, and the interest rate at which wholesale traders borrow. The key prediction of the standard model is that $\beta_{a}>\beta_{b}$, owing to a rise in competition and the interest rate following the DOT ban. The change in the intercept $\gamma_{a}-\gamma_{b}$ is of independent interest, as it helps estimate the effect of the reform on the level of downstream prices. The standard model

\footnotetext{
${ }^{21}$ If the standard model is extended to incorporate capacity constraints which cause use unit costs to rise with quantity, it predicts higher passthrough when the import price is high. See the discussion in Section 8.
} 
predicts that $\gamma_{a}-\gamma_{b}<0$. Hence we are interested in a regression of the form

$$
P_{\tau}=\theta_{0}+\theta_{1} d_{l}+\theta_{2}\left[P_{\tau m}+C_{\tau}\right]+\theta_{3} d_{l}\left[P_{\tau m}+C_{\tau}\right]+\epsilon_{\tau}
$$

where $d_{l}$ is a regime dummy ( 1 after the reform, 0 before), and identifying the signs of coefficients of the reform dummy $\theta_{1}\left(=\gamma_{a}-\gamma_{b}\right)$ and its interaction with the import price $\theta_{3}\left(=\beta_{a}-\beta_{b}\right)$. We refer to this as the before-after regression.

The key difficulty with the before-after approach is that we do not have data on costs of refiners, and financing and distribution costs of wholesale traders. When these costs are correlated with the import price, the estimated pass-through will be biased if the correlation varies significantly between the pre- and post-reform periods. ${ }^{22}$ In the online appendix, we report some evidence on such correlations with the diesel price, and the estimates of the effects of the reform from the before-after regression (in Table T1). However, in general, it is not possible to empirically verify the assumption of constant correlation for all the different components of the costs of the refiners and the traders. Moreover, it is not possible to make inferences regarding the changes in the intercept term on the basis of the before-after regression, and, as a result, we cannot assess the effects of the reform on the level of the wholesale and consumer (retail) prices. ${ }^{23}$

A more credible approach would be a difference-in-difference (DiD) design which compares price movements in palm oil with that in other commodities with similar vertical distribution channels, and comparable storage and transport costs. We use wheat and lentil as the comparison commodities in our DiD analysis, as they are also mostly imported from abroad in Bangladesh flowing through similar vertical chains, and are subject to similar transport and storage costs. ${ }^{24}$ The reform did not apply to wheat or lentils, so their supply chains were not

\footnotetext{
${ }^{22}$ This omitted variables bias remains important even if the marginal costs of the traders are constant as assumed in the standard model, and thus do not affect the passthrough rate directly.

${ }^{23}$ In addition to possible changes in the correlation between omitted distribution costs and import price, any changes in the average distribution costs across the pre- and post-reform periods would cause bias in the estimate of the effects of the reform on the intercept from a before-after regression.

${ }^{24}$ Storage and transport costs are not commodity specific as all three commodities are nonperishable.
} 
affected. This leads to a DiD regression using data which pools oil, wheat and lentil:

$$
P_{\tau}=\theta_{0}+\theta_{1} d_{l}+\theta_{2} P_{\tau m}+\theta_{3}\left(d_{l} * P_{\tau m}\right)+\lambda_{1} d_{O}+\lambda_{2}\left(d_{O} * P_{\tau m}\right)+\lambda_{3}\left(d_{O} * d_{l}\right)+\lambda_{4}\left(d_{O} * d_{l} * P_{\tau m}\right)+\epsilon_{\tau}^{*}
$$

where $d_{O}$ denotes an oil dummy, and the prices $P_{\tau}$ and $P_{\tau m}$ now include palm oil, wheat, and lentils. Then $\lambda_{3}$ and $\lambda_{4}$ would provide estimates of the effect of the reform on the intercept and pass-through rates in oil. Since the storage rental rates and transport rates do not vary across palm oil, wheat and lentil, the distribution costs in oil on the one hand, and wheat and lentil on the other will co-move, and the estimates from the DiD design will be less biased than the before-after regression using data on oil alone. ${ }^{25}$ Naturally, the credibility of the DiD research design depends on the validity of the parallel trends assumption. The fact that we have daily data on prices for a long period from the pre-reform regime allows us to implement multiple tests of the validity of parallel trends at various points of time.

A final issue in assessing the effects of the reform on passthrough rate is a possible confounding effect of changes in bank interest rate in the post-reform period because of factors unrelated to the reform such as central bank policy. One might worry that if the bank interest rate fell significantly due to central bank policy independent of the policy reform in the edible oils market, the interest rate paid by the wholesale traders may have fallen compared to the pre-reform period. Then the standard model would be consistent with a lower pass-through after the reform. The evidence on bank interest rates actually shows the opposite: the interest rate increased following the reform. ${ }^{26}$ Since the wholesale traders of wheat and lentils could rely on the financial intermediaries, while the oil traders lost their access after the reform, the DiD design captures the effects of higher interest rates paid by oil traders when borrowing from the banks. This would bias our results in a direction that would strengthen our conclusion that reform caused passthrough to decline in edible oils.

\footnotetext{
${ }^{25}$ This specification of the DiD regression does not allow for the passthrough to vary between the comparison commodities: wheat and lentil. The estimates from the alternative specification where wheat and lentil passthrough rates can be different are reported in the online appendix Table T.1.

${ }^{26}$ The average interest rate on short-term bank loans increased from 11.46 to 13.38 in the post-reform period.
} 


\section{$7 \quad$ Data and Empirical Results}

We use daily price data for palm oil, wheat and lentil at various stages of the supply chain from the Department of Agricultural Marketing (DAM) unit of Ministry of Agriculture, Bangladesh Government. These data are very similar to daily price data reported by The Trading Corporation of Bangladesh (TCB) for major urban centers. We utilize the DAM data owing to longer coverage and across multiple commodities. Daily international prices of wheat are derived from the data stream of Chicago Board of Trading. Crude palm oil price data is obtained from the Malaysian Palm oil Board. ${ }^{27}$ Lentil import prices are taken from the National Bureau of Revenue daily import data. Our "full sample" extends from January 24, 2008 to October 4, 2012. There are some data gaps due to lack of price data during weekends and holidays as well as some missing data in the DAM original data set. However, the main estimation sample we use for our empirical analysis consists of data from 1 year before the implementation of the reform, excluding the announcement period and the observations corresponding to low import prices. Later we use alternative samples including the announcement period and the low prices to check robustness of our conclusions.

Table 1 provides summary statistics for our main estimation sample on wholesale, retail and import prices of palm oil, wheat, and lentil prior to the reform. Figure 1 plots wholesale price data for palm oil along with the crude import price over the the main sample period used for estimation. The close co-movement between the two series is apparent, with a margin that moves counter-cyclically, suggesting a pass-through rate between 0 and 1 . The two vertical lines in the middle of 2011 correspond to dates of announcement and implementation of the reform. The import price was rising continuously from late 2008 onwards, until a few months prior to the onset of the reform. This was reversed thereafter immediately for a few months following the reform. Despite this the wholesale price remained stationary, resulting in an increase in the margin, suggesting that pass-through declined following the reform.

Figure 2 compares movements in wholesale trading margins for palm oil with the average

\footnotetext{
${ }^{27}$ Crude palm oil was listed in the TCB in January 2009. We compared TCB data with Malaysian Palm Board data on daily palm oil prices, there are nearly identical.
} 
margin for wheat and lentil (calculated as average wholesale price minus average import price). Prior to the reform, the two tend to move together, with the troughs and peaks in the average wheat and lentil margin tracking those in palm margin well. ${ }^{28}$ A widening gap between the margins opens up in the post reform period, with the margin in palm oil higher, and the margins seem to converge again at the end of the sample period. Estimates of the margins reported in the online appendix suggest a $25 \%$ or higher rise in oil margins while the margin for both wheat and lentil fell slightly. This preliminary evidence suggests that the primary goal of the reform to reduce trader's margin did not materialize; the effects of the reform might have been the opposite of what was intended by the policy makers.

\subsection{Passthrough in the Pre-reform Period: Evidence on Asymmetry and Variation with Crude Import Price}

Tables $2 \mathrm{a}$ and $2 \mathrm{~b}$ show estimates of the passthrough of import price of crude palm oil to the wholesale prices of palm oils for different phases: (i) high vs. low prices, and (ii) rising vs. falling prices in the international market. The sample consists of data from the pre-reform (announcement) period. The first two columns in Table 2a report the estimated passthrough of the import price of crude palm oil to the wholesale price during the high vs. low international price regimes (where the high regime is defined by above-median prices). The evidence is clear that the passthrough rate is substantially lower in the high-price regime, 0.14 (high-price) vs. 0.83 (low-price). The null hypothesis that the passthrough rates are equal across high and low price regimes is rejected at the 1 percent level. This is consistent with the credit rationing model, but rejects the standard model. Similarly, for wheat, the passthrough is significantly lower during high world prices, while the passthrough rates are not significantly different for lentil across high and low price regimes.

The first two columns in Table $2 \mathrm{~b}$ test whether the passthrough rate differed between phases when prices were falling or rising in the international market. The estimates of passthrough

\footnotetext{
${ }^{28}$ The margins are calculated using 4-week lagged import price to reflect delays caused by transport and processing. Our main empirical estimates also focus on the pass-through of 4-week lagged import prices.
} 
rates are similar in magnitude across falling and rising prices regimes, and the null hypothesis of equal passthrough across the market phases cannot be rejected ( $\mathrm{p}$-value $=0.95$ ). The evidence in the last four columns show that there is no evidence of asymmetry in price passthrough for wheat and lentil either. This is consistent with the simple static versions of both the standard and the credit rationing models that we have considered in this paper.

\subsection{The DiD Estimates}

The evidence in Table 2a that passthrough of oil prices vary significantly with the level of international prices has important implications for suitable choice of data samples for our subsequent tests of the effects of the policy reform. The post-reform period corresponded to a high price regime in the international market for crude palm oil. Our main empirical results from the DiD approach below are therefore based on a sample that includes only data from the high-price regime during the pre-reform period. To check robustness, we also report estimates from the full sample. A second issue is the choice of the time window for the pre-reform period. Although we have data from a long period (2 years) from before the reform, one might worry that as we move away from the date of reform, the possibility of other exogenous factors contaminating the DiD design increases. To address this, we focus on the sample consisting of data from the 1 year period immediately before the reform for our main results, and report the corresponding estimates using the 2 years pre-reform sample as part of the robustness checks.

To test the parallel trend assumption underlying the DiD analysis, we estimate the effects of placebo reforms in the pre-reform sample (1 year period immediately before the implementation of the reform). We define fictitious reform dates at many arbitrary points in time during the pre-reform period and estimate the "effects" of these placebo reforms in DiD regressions with wheat and lentils as the comparison commodities. If the identifying assumption of parallel prereform trends is violated, we should observe significant effects of these placebo reforms. The effects of six such placebo reforms on the edible oils price passthrough rate are shown in Figure 3 along with the 95 percent confidence intervals; all of them fail to reject the null hypothesis of parallel trends. Table 3 reports the full estimates for two additional placebo reforms (dated 
3 months, 6 months before the announcement of the reform) which again do not reject the identifying assumption.

\subsection{Effects of the DOT Ban: DiD Estimates}

Table 4 presents results of the DiD regressions for the actual reform where the reform dummy takes on the value of 1 when an observation comes from the period after the policy reform took effect on June 21, 2011. The dependent variable in the regressions is the wholesale price and the 4 -week lagged import price is the independent variable of interest. We check the robustness of the results later with alternative lags for import price. ${ }^{29}$ The regressions include year and quarter dummies, and a dummy for the Ramadan period when food prices tend to spike. We exclude data for the few months between the date of announcement and implementation of the reform. ${ }^{30}$

Based on a correlogram analysis of price data, we allow for an AR (3) process in the residuals. The null hypothesis of a unit root in the residual is rejected at the 1 percent level by augmented Dickey-Fuller and panel unit root tests for all of the price regressions reported in this paper. Standard errors are corrected for heteroskedasticity and autocorrelation using the Newey-West (1987) procedure.

The first two columns in Table 4 report the estimates from the DiD regressions (column 1 without controls for distribution costs, and column 2 with controls). The results show that the reform reduced the price passthrough rate for edible oils, but increased the intercept of the price equation. ${ }^{31}$ These conclusions are robust to allowing passthrough to vary between wheat and lentil. ${ }^{32}$ The next two columns in Table 4 show the estimates from the DiD regressions with

\footnotetext{
${ }^{29}$ The 4 -week lag is chosen to reflect the fact that it takes about 10-14 days to transport the crude oil from Malaysia to Chittagong port after an order is placed, and then the oil needs to be transported to the mills and refined which require approximately 2 more weeks. The conclusions of this paper, however, do not depend on this particular lag assumption. See the evidence based on alternative lags below.

${ }^{30}$ Later we show that the conclusions are robust to the inclusion of data for these months in the sample.

${ }^{31}$ Compared to the estimates from the before-after approach reported in the online appendix, the fall in the pass-through rate and the rise in the intercept are both larger. This suggests substantial biases in the before-after estimates. For a fuller discussion on the nature of the biases, see the online appendix.

${ }^{32}$ This is shown in appendix Table T2 which uses a more flexible specification of the DiD model with different passthrough rates for wheat and lentil. All specifications in this paper allow for different intercepts for wheat
} 
wheat only (column 3) or lentils only (column 4) as the comparison commodity; the estimates again deliver the similar conclusions. The last column (i.e., column 5) takes advantage of the fact that we have more than one comparison commodity: we see that the reform did not affect passthrough of a placebo treatment commodity (say wheat) in comparison to the other (lentils).

Table 5 shows the results from a series of robustness checks. ${ }^{33}$ The first two columns show results when the estimation sample includes the announcement period (column 1) and data from the pre-reform low price regime (column 2). The conclusions regarding the effects of the reform on the passthrough rate and the intercept remain unchanged. The next two columns in Table 5 relate to robustness with respect to the lags in the import price. Instead of the four week lag used in Table 4, column (3) uses no lag, and column (4) adopts a 8-week lag for the import price of crude palm oils. These correspond to alternative hypotheses concerning the way refiners set prices for refined oil, based on historic or current cost, and alternative specifications of the lag between the time of import of crude oil and sale of refined oil. The central conclusions from Table 4 are robust to such alternative specifications of the lag in import price used for estimation. The last column of Table 5 shows that the results continue to hold when the prereform sample is expanded to include two years. As to be expected, the numerical magnitudes differ across these different lag specifications and data samples.

Observe also that the estimates in Tables 4 and 5 imply that the effect of the reform on the level of the wholesale price was positive. For instance, Columns 1 and 2 in Table 4 indicate an increase in the intercept by between 48-50 taka, which outweighs the effect of a lower passthrough ( 0.55 multiplied by the average import price of between $75-80$ taka). The same is true for all the estimates reported in Table 5. This is consistent with the prediction of the credit rationing model that pass-through will decline if the price level rises. If we estimate a simple DiD specification without allowing for changes in the passthrough rate following the reform, the increase in the price level is larger; the estimates imply a 10.41 taka higher wholesale price

and lentil price equations.

${ }^{33}$ The specification used in Tables 5 and 6 below correspond to the specification in the odd columns in Table 4 with wheat and lentils as the comparison commodities, but without diesel price and exchange rate as additional controls. The results are similar if we include the proxies for distribution costs. The estimates are available upon request. 
level during the post-reform period as compared to an estimate of about 6.50 taka higher price from Table 4 (evaluated at the mean price level).

The exact period for which the effects of the reform lasted is unclear, as the ban on the operation of DOTs started to unravel gradually about 6 months after the implementation of the reform. According to informal accounts, the reform was in place for about a year. Table 6 thus separates the post-reform period into the first 9 months following the reform, from the post-9 month period. The DiD results show that the effects were concentrated in the first 9 months; the 9-month effect was larger than the effects in the previous tables which pooled all postreform dates into a single post-reform period. The estimates for the post 9-month period show a substantial weakening in the effects of the reform. In the online appendix, we report estimates for the first 5 months, for 5-10 months after the reform, and after 10 months separately; the evidence suggesting monotonically declining magnitude of the effects of the reform (see Figures F1 and F2).

Our analysis predicts that the reform affected the wholesale margin (i.e, wholesale price import price) but did not directly affect the wholesale-retail margin, since it affected DOTs who intermediated between the refiners and the wholesalers. This would imply that the effects on the retail margin (consumer price less the oil import price) would be similar to those for the wholesale margin. ${ }^{34}$ The first column in Table 7 presents the results for the retail margin for our main estimation sample used for the estimates in Table 4. These are very similar to the results in Table 4 for the wholesale margin. Column 2 of Table 7 shows that the effects for the first 9 months following the reform had similar but somewhat larger effects on the retail margin (compared with the effects on the wholesale margin shown in Table 6).

\section{Supplementary Evidence and Alternative Explanations}

We now discuss additional but less formal evidence consistent with our finding of an increase in the wholesale price of palm oil resulting from intensified credit constraints of wholesalers

\footnotetext{
${ }^{34}$ However, if the reform had some (weaker) effects on the retail margins, the total impact on the consumer prices may be somewhat larger than what is suggested by the estimates for the wholesale prices.
} 
following the reform. Choudhury and Clara Costa (2012) provide case studies of the experience of two refiners (Nurjahan Group and Bangladesh Edible Oils Limited) following the reform. Owing to a drop in the demand from wholesalers (and the SO dealers), these two refiners accumulated excess inventories, and thereafter lowered their imports of crude oil by $39 \%$ between 2010 and 2011. Consistent with this account, aggregate imports of crude oil for Bangladesh as a whole fell following the reform: see Figure 4 which plots monthly imports for 2009-10 and 2010-11. A simple before-after regression indicates a statistically significant decline following the reform (the coefficient of reform dummy is negative and significant at the 5 percent level). It is striking that this happened during a period when world oil prices were declining, reversing the trend for the previous years (as seen in Figure 1).

Do the estimates seem plausible in magnitude? The DiD estimates for the first 9 months in Table 6 imply that the wholesale price was 9.29 taka higher, i.e., a 11.34 percent increase in prices as a result of the reform (evaluated at the median import price). This price increase is statistically significant at the 1 percent level; a formal test of the null hypothesis of no effect of the reform (at the median import price) yields $F=58.70$. As noted earlier, the DiD estimates capture the effects of both the bank interest rate and tighter credit rationing faced by the traders when borrowing from the banks. According to the central bank (Bangladesh Bank), the average interest rate on short-term bank loans increased by 2 percentage points in the post reform period. Can this increase in interest rate alone account for the higher prices? The median wholesale price of palm oil in the post-reform period was 92 taka, which would suggest a maximum of 1.84 taka higher prices due to the higher bank interest rates caused by factors unrelated to the reform. ${ }^{35}$ This in turn implies 7.45 taka higher prices because of the reform which amounts to a 9.5 percent increase in prices.

However, the effects of the credit limits applied only to traders who switched from the DOTs to the banks after the reform; it is possible that at least some traders were able to arrange alternative financing. In 2013, two years following the reform, we conducted a survey of edible oil traders in the Dhaka and Chittagong markets (Emran et al. (2015)). Data on

\footnotetext{
${ }^{35}$ This assumes a 100 percent passthrough of interest costs to prices.
} 
6176 transactions between DOTs and wholesalers revealed that $30 \%$ of transactions between DOTs and wholesalers were on credit, and supplier credit from DOTs accounted for 32 percent of the volume. A retrospective survey we conducted in February 2016 of a sub-sample of 50 wholesale traders buying on credit from DOTs prior to the reform shows a $45 \%$ reduction in volume. This suggests that the aggregate supply at the wholesale level should drop by approximately $15 \%$ after the reform, assuming that all of the previously DOT-dependent traders experienced a $45 \%$ reduction in volume on average. The available estimate for edible oils demand in Bangladesh suggests a price elasticity of 1.16 (Talukder (1990)). ${ }^{36}$ This yields a back-of-the-envelope estimate of a price increase of about $13 \%$ owing to the $15 \%$ quantity reduction after the reform. This is higher than the DiD estimate of a $9.5 \%$ increase, suggesting some of the traders previously dependent on the DOTs were able to find alternative sources of financing from other informal channels that were less expensive and constraining than the banks.

A possible alternative explanation of the rise in wholesale price is that the reform inadvertently increased the market power at some layer of the vertical chain despite the policy goal of de-concentrating the market. The refiner layer seems the most likely locus of such market power because it is the most concentrated with only 9 refiners who were selling directly to wholesalers, rather than indirectly through the 300 DOTs prior to the reform. This would have implied an increase in total profits earned by the refiners, who would then have a vested interest in ensuring that the reform was not reversed. Interviews with the refiners and traders, as well as the retrospective survey of 50 traders we conducted in February 2016 instead report that the refiners were unhappy with the reform (owing to the limited take up from the sales order (SO) dealers in the new system) and surreptitiously went back to the DOTs to offload their accumulated inventory. This indicates that the refiners' profit was adversely affected by the reform, consistent with the prediction of the credit rationing model. ${ }^{37}$

\footnotetext{
${ }^{36}$ An estimate for edible oils price elasticity in USA is 1.24 (Kojima et al. (2014)).

${ }^{37}$ As noted by an anonymous referee, if the ban on the DOTs were enforced only selectively then the number of DOTs would be smaller in the post-reform period with increased market power, and consequently, the lower passthrough rate after the reform would be consistent with the predictions of the standard model. However, the evidence does not support this possibility as no DOT was able to operate after the reform. More important
} 
We have already explained at the end of Section 4 that the results cannot be explained by rising costs of capacity utilization, as a model with such a feature but without credit rationing makes opposite predictions concerning how passthrough varies with the oil import price and the reform. Search cost based explanations also do not seem plausible. ${ }^{38}$ Search costs did not seem significant prior to the reform, as DOTs operate within a very narrow market area in Dhaka and Chittagong, and wholesale traders could find out prices quoted by the DOTs by making a telephone call to their contacts in these market areas. Following the reform, there were only 9 refiners from whom they could purchase; finding out what prices they were charging would have been even easier than checking prices charged by the 300 DOTs previously.

Yet another possibility is that the quantity caps imposed on the newly appointed SO dealers were binding and the resulting reduction in quantity led to higher prices after the reform. This explanation, however, is not consistent with the fact that many of the SO dealers were not taking delivery of the entitled oil, and the refiners were facing unwanted stockpiles of refined oils which ultimately unraveled the reform.

\section{Summary}

To discriminate between the models of supply chains with and without quantitative credit rationing, this paper studies a policy experiment in Bangladesh where the government banned a layer of financial intermediaries in edible oils market in 2011. The reform was motivated by widely held belief that these intermediaries exert market power, which keeps consumer prices high and lower pass-through of crude import costs. These expectations were consistent with the predictions of a a standard double marginalization model without credit rationing. We first showed that these predictions can get reversed in the presence of financial contracting frictions that result in binding credit constraints for downstream traders.

is the fact that the 300 DOTs in the Dhaka and Chittagong markets were replaced with more than 7000 SOdealers, making the market more competitive. The credit rationing model can explain the lower passthrough rate even though the reform was successful in creating more competition.

${ }^{38}$ Chau et al. (2016) and Casaburi et al. (2013) emphasize search costs in contexts where small farmers search for the best price offered by middlemen. 
We then tested the competing predictions of the two models, using a difference-in-difference (DiD) design with wheat and lentil as the comparison commodities because, like palm oil, they incur similar distribution costs and are imported into Bangladesh. A series of placebo reforms using data from the pre-reform period provided evidence in favor of the parallel trends assumption underlying the $\mathrm{DiD}$ research design. The estimates of the effects of the reform from the DiD approach shows that, contrary to the expectations of the policy makers, the reform raised consumer prices and reduced pass-through of crude import prices. Therefore, credit market frictions and quantitative credit rationing are important in understanding how international price shocks are transmitted to domestic wholesale and retail (consumer) prices in developing countries, and in the formulation of regulatory policies.

\section{References}

Atkin, D and D. Donaldson (2015), Who's Getting Globalized? The Size and Implications of Intra-national Trade Costs, Working paper, Stanford University.

Bardhan, Pranab K. (1984). Land, Labor, and Rural Poverty: Essays in Development Economics. Delhi: Oxford University Press/New York: Columbia University Press.

Bardhan, Pranab K.(1980). "Interlocking Factor Markets and Agrarian Development: A Review of Issues". Oxford Economic Papers 32.1 (1980): 82-98.

Berman, N., P. Martin, and T. Mayer (2012): "How do different exporters react to exchange rate changes?", Quarterly Journal of Economics, 127, pp. 437-492.

Bonnet, C., P. Dubois, S. Villas-Boas, and D. Klapper (2013): "Empirical evidence on the role of nonlinear wholesale pricing and vertical restraints on cost pass-through", Review of Economics and Statistics, Vol. 95, No. 2, pp. 500-515.

Braverman, A and J. Stiglitz (1982), "Sharecropping and the Interlinking of Agrarian Markets". American Economic Review, 72, 695-715.

Breitung, J. (2000), The local power of some unit root tests for panel data. Advances in Econometrics, Volume 15: Nonstationary Panels, Panel Cointegration, and Dynamic Panels, ed. B. H. Baltagi, 161-178. Amsterdam: JAY Press. 
Burkart, M, and T. Ellingsen (2004), "In-Kind Finance: A Theory of Trade Credit", American Economic Review, June 2004.

Burstein, A., and G. Gopinath (2013): 'International prices and exchange rates', Handbook of International Economics, Volume IV, Elsevier

Carpenter, F., 1866. Six Months at the White House with Abraham Lincoln. Hurd, New York. Casaburi L., Rachel Glennerster and Tavneet Suri (2013), Rural Roads and Intermediated Trade: Regression Discontinuity Evidence from Sierra Leone, Working paper, Stanford University.

Casaburi L. and T. Reed (2017), Competition in Agricultural Markets: An Experimental Approach, Working Paper, University of Zurich.

Chau, Nancy H \& Goto, Hideaki \& Kanbur, Ravi, (2016). "Middlemen, Fair Traders and Poverty," Journal of Economic Inequality, 14: 81-108.

Emran, M. S, D. Mookherjee, F Shilpi, and H. Uddin (2015), Trading Margins and Contracts in a Vertical Marketing Chain: Evidence from Edible Oils Market in Bangladesh, Working Paper, World Bank.

Gita Gopinath \& Oleg Itskhoki \& Roberto Rigobon, 2010. "Currency Choice and Exchange Rate Pass-Through," American Economic Review, American Economic Association, vol. 100(1), pages 304-336, March.

Greif, Avner, (1993). "Contract Enforceability and Economic Institutions in Early Trade: the Maghribi Traders' Coalition," American Economic Review, American Economic Association, vol. 83(3), pages 525-548, June.

Goldberg, P., and R. Hellerstein (2008): "A structural approach to explaining incomplete exchange-rate pass-through and pricing-to-market", American Economic Review, Vol. 98, No. 2, pp. 423-429.

Harris, R. D. F., and E. Tzavalis. (1999). "Inference for unit roots in dynamic panels where the time dimension is fixed". Journal of Econometrics 91: 201-226. 
Im, K. S., M. H. Pesaran, and Y. Shin. (2003). "Testing for unit roots in heterogeneous panels". Journal of Econometrics 115: 53-74.

Ivanic, M. and W. Martin, and H. Zaman, 2012. "Estimating the Short-Run Poverty Impacts of the 2010-11 Surge in Food Prices", World Development, Elsevier, vol. 40(11), pages 2302-2317. Kojima, Y, J. Parcell, J. Cain (2014), A Demand Model of the Wholesale Vegetable Oils Market in the U.S.A, Working paper.

Kreps, David M, and Jose A Scheinkman. 1983. "Quantity precommitment and Bertrand competition yield Cournot outcomes. The Bell Journal of Economics 326-337.

Lenin, V.I., 1964. Complete Collected Works, vol. 35. Moscow.

Macchiavello, R and A. Morjara (2016), Competition and Relational Contracts: Evidence from Rwanda's Coffee Mills, mimeo, LSE and Kellog.

Minten, Bart \& Kyle, Steven, 1999. "The effect of distance and road quality on food collection, marketing margins, and traders' wages: evidence from the former Zaire", Journal of Development Economics, Elsevier, vol. 60(2), pages 467-495, December.

Mitra, Sandip \& Mookherjee, Dilip \& Torero, Maximo \& Visaria, Sujata, (2018). "Asymmetric Information and Middleman Margins: An Experiment with Indian Potato Farmers," Review of Economics and Statistics, 100 (1), 1-13.

Nakamura, E., and D. Zerom (2010): “Accounting for Incomplete Pass-Through", Review of Economic Studies, Vol. 77, No. 3, pp. 1192-1230.

Nakamura, E (2008). "Pass-Through in Retail and Wholesale," American Economic Review, American Economic Association, vol. 98(2), pages 430-437, May.

Rust, J \& George Hall, (2003). "Middlemen versus Market Makers: A Theory of Competitive Exchange," Journal of Political Economy, University of Chicago Press, vol. 111(2), pages 353403, April.

Smith, J K (1987), "Trade Credit and Informational Asymmetry." Journal of Finance, September, 1987, 42(4), pp. 863-69. 
Srinivasan, P V (2005), Impact of Trade Liberalization on India's Oilseed and Edible oils sector, IGIDR, Working Paper.

Talukder, R. K, (1990), "Food Consumption Parameters in Bangladesh: Implications for Food Policy", Bangladesh Journal of Agricultural Economics, December 1990.

Uddin, H and M. Taslim (2010), An Assessment of Competition in the Edible Oil Market of Bangladesh, Bureau of Economic Research, University of Dhaka, Bangladesh.

Weyl, E. G., and M. Fabinger (2013): "Pass-Through as an Economic Tool: Principles of Incidence under Imperfect Competition", Journal of Political Economy, Vol. 121, No. 3, pp. 528- 583. 
Table 1: Summary Statistics

\begin{tabular}{lcccc}
\hline & \multicolumn{4}{c}{ Samples consist of post-reform plus } \\
& \multicolumn{2}{c}{ 1-year Pre-reform } & 2-Year Pre-reform \\
\cline { 2 - 5 } & & SD & Mean & SD \\
\hline Palm & 85.98 & 10.59 & 78.71 & 15.06 \\
Wholesale price & 90.32 & 11.14 & 82.71 & 15.77 \\
Retail price & 73.00 & 11.47 & 66.64 & 14.51 \\
World Price (4 week & 74.76 & 11.46 & 67.99 & 15.00 \\
lagged) & & & & \\
World Price (Current) & 23.91 & 2.05 & 23.91 & 2.05 \\
Wheat & 26.50 & 2.34 & 26.50 & 2.34 \\
Wholesale price & 18.60 & 1.54 & 18.60 & 1.54 \\
Retail price & 18.82 & 2.50 & 18.82 & 2.50 \\
World Price (4 week & & & & \\
lagged) & 66.74 & 4.53 & 70.24 & 7.73 \\
World Price (Current) & 74.20 & 3.95 & 77.29 & 6.99 \\
\hline Lentil & 56.32 & 4.45 & 58.36 & 5.57 \\
Wholesale price & 56.34 & 5.37 & 58.26 & 6.16 \\
Retail price & & &
\end{tabular}

Notes: (1) SD stands for Standard Deviation. (2) The "1-year pre-reform" Includes 1 year before the announcement date of reform, "2-year pre-reform sample" spans 2 years before the announcement date of reform. The announcement period (90 days) is excluded from both samples. The 1-year pre-reform sample covers June 3, 2010 to October 4, 2012, and the 2-year pre-reform sample covers from May 31, 2009 to October 4, 2012. There are gaps in data due to weekends and festivities. (3) Unit for Palm is Litre, and for Wheat and Lentil Kg. (4) All prices are in the local currency, Taka. 
Table 2a: Wholesale Price Pass-Through during Pre-reform period: High vs. Low World Price

(Dependent Variable Wholesale Prices)

\begin{tabular}{|c|c|c|c|c|c|c|}
\hline & \multicolumn{2}{|c|}{ Palm } & \multicolumn{2}{|c|}{ Wheat } & \multicolumn{2}{|c|}{ Lentil } \\
\hline & $\begin{array}{c}\text { High Price } \\
\text { (1) }\end{array}$ & $\begin{array}{c}\text { Low Price } \\
(2)\end{array}$ & $\begin{array}{c}\text { High Price } \\
\text { (3) }\end{array}$ & $\begin{array}{c}\text { Low Price } \\
\text { (4) }\end{array}$ & $\begin{array}{c}\text { High Price } \\
\text { (5) }\end{array}$ & $\begin{array}{c}\text { Low Price } \\
(6)\end{array}$ \\
\hline World Price & $\begin{array}{c}0.139 \\
(0.127)\end{array}$ & $\begin{array}{c}0.828 * * * \\
(0.0784)\end{array}$ & $\begin{array}{c}0.879 * * * \\
(0.169)\end{array}$ & $\begin{array}{c}1.800 * * * \\
(0.129)\end{array}$ & $\begin{array}{c}0.839 * * * \\
(0.175)\end{array}$ & $\begin{array}{c}0.752 * * \\
(0.314)\end{array}$ \\
\hline Constant & $\begin{array}{c}79.70 * * * \\
(10.27)\end{array}$ & $\begin{array}{c}22.31 * * * \\
(4.149)\end{array}$ & $\begin{array}{c}10.23 * * * \\
(3.117)\end{array}$ & $\begin{array}{c}-5.207 * * * \\
(1.626)\end{array}$ & $\begin{array}{c}22.70 * * \\
(11.17)\end{array}$ & $\begin{array}{l}27.87 * \\
(16.59) \\
\end{array}$ \\
\hline \multicolumn{7}{|c|}{ Test of equality of coefficients } \\
\hline $\begin{array}{l}\text { F-statistics } \\
\text { P-value }\end{array}$ & \multicolumn{2}{|c|}{29.42} & \multicolumn{2}{|c|}{29.82} & & \\
\hline Observations & 143 & 402 & 186 & 346 & 266 & 83 \\
\hline
\end{tabular}

Notes: The estimation sample is the entire pre-reform period (January 24, 2008-March 22, 2011). High (low) price sample is defined as all periods when world price of the imported input is higher (lower) than median (over the entire sample including post-reform period). Standard errors in parentheses, $* * * \mathrm{p}<0.01, * * \mathrm{p}<0.05, * \mathrm{p}<0.1$

Table 2b: Pass-Through During Pre-reform period: Test of Asymmetry

(Dependent Variable Wholesale Prices)

\begin{tabular}{|c|c|c|c|c|c|c|}
\hline & \multicolumn{2}{|c|}{ Palm } & \multicolumn{2}{|c|}{ Wheat } & \multicolumn{2}{|c|}{ Lentil } \\
\hline & $\begin{array}{c}\text { Falling Price } \\
(1)\end{array}$ & $\begin{array}{c}\text { Rising Price } \\
\text { (2) }\end{array}$ & $\begin{array}{c}\text { Falling Price } \\
(3) \\
\end{array}$ & $\begin{array}{c}\text { Rising Price } \\
(4)\end{array}$ & $\begin{array}{c}\text { Falling Price } \\
(5)\end{array}$ & $\begin{array}{c}\text { Rising Price } \\
(6)\end{array}$ \\
\hline World Price & $\begin{array}{c}0.487 * * * \\
(0.105)\end{array}$ & $\begin{array}{c}0.494 * * * \\
(0.0732)\end{array}$ & $\begin{array}{c}0.863 * * * \\
(0.119)\end{array}$ & $\begin{array}{c}0.863 * * * \\
(0.0937)\end{array}$ & $\begin{array}{c}0.408 * * \\
(0.195)\end{array}$ & $\begin{array}{c}0.227 * * * \\
(0.0532)\end{array}$ \\
\hline Constant & $\begin{array}{c}51.27 * * * \\
(7.236)\end{array}$ & $\begin{array}{c}49.73 * * * \\
(6.260)\end{array}$ & $\begin{array}{c}13.52 * * * \\
(2.715)\end{array}$ & $\begin{array}{c}8.912 * * * \\
(1.757)\end{array}$ & $\begin{array}{c}53.99 * * * \\
(12.73)\end{array}$ & $\begin{array}{c}55.85 * * * \\
(3.030)\end{array}$ \\
\hline \multicolumn{7}{|c|}{ Test of equality of coefficients } \\
\hline F-statistics & \multicolumn{2}{|c|}{0.00} & \multicolumn{2}{|c|}{0.00} & \multicolumn{2}{|c|}{0.87} \\
\hline P-value & 0.95 & & 0.99 & & 0.35 & \\
\hline Observations & 273 & 272 & 205 & 327 & 176 & 173 \\
\hline
\end{tabular}

Notes: The estimation sample is the entire pre-reform period (January 24, 2008-March 22, 2011). Standard errors in parentheses, *** $\mathrm{p}<0.01, * * \mathrm{p}<0.05, * \mathrm{p}<0.1$ 
Table 3: Test of Parallel Trends between Wheat/Lentil and Oil Prices in Pre-reform Period (Dependent Variable Wholesale Prices)

\begin{tabular}{lcc}
\hline & \multicolumn{2}{c}{$\begin{array}{c}\text { Fictitious Policy Reform before X months of } \\
\text { announcement of actual reform }\end{array}$} \\
\cline { 2 - 3 } & X $=6$-month & X 3 -month \\
& $(1)$ & $(2)$ \\
\hline Fictitious Reform Dummy & $-31.37^{* * *}$ & $3.198^{* * *}$ \\
Reform Dummy*Palm Dummy & $(8.224)$ & $(1.016)$ \\
& $\mathbf{- 1 0 . 6 8}$ & $\mathbf{1 9 . 6 7}$ \\
Reform Dummy*Palm Dummy* World & $\mathbf{( 2 0 . 2 2 )}$ & $\mathbf{( 1 0 . 2 4 )}$ \\
Price & $\mathbf{0 . 4 3 2}$ & $\mathbf{0 . 2 4 3}$ \\
& $\mathbf{( 0 . 3 8 2 )}$ & $\mathbf{( 0 . 1 4 7 )}$ \\
Reform Dummy*World Price & $0.468^{* * *}$ & $-0.152^{* * *}$ \\
& $(0.131)$ & $(0.0242)$ \\
\hline World Price*Palm Dummy & 0.0151 & $0.716^{* * *}$ \\
& $(0.371)$ & $(0.105)$ \\
World Price & $-0.307^{* * *}$ & -0.00473 \\
& $(0.107)$ & $(0.0520)$ \\
Palm Dummy & 27.45 & 7.018 \\
& $(19.86)$ & $(5.210)$ \\
\hline Intercept & 52.81 & -98.33 \\
& $(71.31)$ & $(88.22)$ \\
\hline Observations & 379 & 379 \\
Year and Quarter dummies & Yes & Yes \\
Lentil Dummy & Yes & Yes \\
Ramadan Dummies & Yes & \\
\hline
\end{tabular}

Notes: (1) The placebo reform is dated 6 and 3 months before the announcement of reform date (March 22, 2011) respectively. (2) Main coefficients of interest are in bold. (3) Pre-reform sample spans from June 3, 2010 to March 22, 2011. (4) Standard errors are corrected using Newey-West (1987) procedure for heteroskedasticity and autocorrelation, assuming AR (3) error process. Standard errors in parentheses, ${ }^{* * *} \mathrm{p}<0.01, * * \mathrm{p}<0.05,{ }^{*} \mathrm{p}<0.1$ 
Table 4: Effects of the Policy Reform on Wholesale Prices: DiD Estimates from High Price Sample (Dependent Variable: Wholesale Prices)

\begin{tabular}{|c|c|c|c|c|c|}
\hline & \multicolumn{4}{|c|}{ Effects on Palm Oil } & \multirow{3}{*}{$\begin{array}{l}\text { Placebo Treatment } \\
\text { Lentil vs. Wheat } \\
\text { (5) }\end{array}$} \\
\hline & \multicolumn{2}{|c|}{$\begin{array}{c}\text { Palm vs Lentil \& } \\
\text { Wheat }\end{array}$} & \multirow{2}{*}{$\begin{array}{c}\text { Palm vs } \\
\text { Wheat } \\
(3) \\
\end{array}$} & \multirow{2}{*}{$\begin{array}{c}\text { Palm vs. } \\
\text { Lentil } \\
(4) \\
\end{array}$} & \\
\hline & $(1)$ & (2) & & & \\
\hline \multirow[t]{2}{*}{ Reform Dummy } & $-5.805 * * *$ & -1.404 & $-14.21 * *$ & $-14.78 * *$ & -3.151 \\
\hline & $(1.141)$ & $(1.453)$ & $(6.571)$ & $(6.667)$ & $(5.703)$ \\
\hline \multicolumn{6}{|l|}{ Reform Dummy*Palm } \\
\hline \multirow[t]{2}{*}{ Dummy } & $47.35 * * *$ & $49.52 * * *$ & $49.80 * * *$ & $63.23 * * *$ & -14.50 \\
\hline & $(7.528)$ & (7.097) & $(8.374)$ & $(\mathbf{1 0 . 8 5})$ & $(8.635)$ \\
\hline \multicolumn{6}{|l|}{ Reform Dummy*Palm } \\
\hline \multirow[t]{2}{*}{ Dummy* World Price } & $-0.532 * * *$ & $-0.544 * * *$ & $-1.229 * * *$ & $-0.775 * * *$ & 0.262 \\
\hline & $(0.102)$ & $(0.0967)$ & $(\mathbf{0 . 3 0 7})$ & $(\mathbf{0 . 1 6 8 )}$ & $(0.309)$ \\
\hline \multirow[t]{2}{*}{ Reform Dummy*World Price } & $0.0422 * *$ & 0.0267 & $0.900 * * *$ & $0.240 * *$ & 0.0206 \\
\hline & $(0.0173)$ & $(0.0169)$ & $(0.328)$ & $(0.119)$ & $(0.281)$ \\
\hline \multirow[t]{2}{*}{ Palm Dummy*World Price } & $0.600 * * *$ & $0.603 * * *$ & $1.002 * * *$ & $0.871 * * *$ & -0.0881 \\
\hline & $(0.0896)$ & $(0.0840)$ & $(0.258)$ & $(0.106)$ & $(0.221)$ \\
\hline \multirow[t]{2}{*}{ World Price } & $0.210 * * *$ & $0.179 * * *$ & -0.302 & -0.0413 & 0.103 \\
\hline & $(0.0685)$ & $(0.0610)$ & $(0.293)$ & $(0.0701)$ & $(0.204)$ \\
\hline \multirow[t]{2}{*}{ Palm Dummy } & 1.662 & 3.312 & 1.027 & $-48.37 * * *$ & \\
\hline & $(3.608)$ & $(3.490)$ & $(4.323)$ & $(6.657)$ & \\
\hline Intercept & $\begin{array}{c}23.52 * * * \\
(1.296)\end{array}$ & $\begin{array}{c}97.60^{* * *} \\
(16.44)\end{array}$ & $\begin{array}{c}95.94 * * * \\
(20.07)\end{array}$ & $\begin{array}{c}140.0^{* * * *} \\
(16.95)\end{array}$ & $\begin{array}{c}111.7 * * * \\
(21.06)\end{array}$ \\
\hline Observations & 1,090 & 1,090 & 684 & 832 & 664 \\
\hline Year and Quarter dummies & Yes & Yes & Yes & Yes & Yes \\
\hline Ramadan Dummies & Yes & Yes & Yes & Yes & Yes \\
\hline Lentil Dummy & Yes & Yes & Yes & Yes & Yes \\
\hline Proxies for Distribution Costs & No & Yes & Yes & Yes & Yes \\
\hline
\end{tabular}

Notes: (1) Reform dummy=1 if an observation is from after the date of the actual reform: June 21, 2011. (2) The sample consists of the period from June 3, 2010 to October 4, 2012, but the announcement phase (90 days) is excluded. Observations for palm, wheat and lentil: Pre-reform: 399; Post reform: 691. (3) Unit for Palm is Litre and for Wheat and Lentil is Kg. (4) Proxies for distribution costs include diesel price and exchange rate. (5) Standard errors are in parentheses and corrected using Newey-West (1987) procedure for heteroskedasticity and autocorrelation, assuming AR (3) process. (6) Augmented Dickey-Fuller and Panel Unit Root Tests Reject the Null Hypothesis of Unit Roots in the Residuals. (7) $* * *$ denotes significant at the 1 percent, and $* *$ at the 10 percent level. 
Table 5: Effects of Reform on Wholesale Price of Palm Oil: Robustness to Alternative Samples and Lags in Crude Palm Oil Price

(Dependent Variable: Wholesale Price)

\begin{tabular}{|c|c|c|c|c|c|}
\hline & \multicolumn{4}{|c|}{ Main Sample (High price \& 1-year pre-reform) } & \multirow{2}{*}{$\begin{array}{l}\text { Two-year } \\
\text { Pre-Reform } \\
\text { and High } \\
\text { Price Sample } \\
\end{array}$} \\
\hline & $\begin{array}{l}\text { Includes } \\
\text { Announcement }\end{array}$ & $\begin{array}{l}\text { Includes } \\
\text { Low Price } \\
\end{array}$ & $\begin{array}{c}\text { No } \\
\text { Lag }\end{array}$ & $\begin{array}{c}8 \text { Week } \\
\text { Lag }\end{array}$ & \\
\hline & $(1)$ & $(2)$ & $(3)$ & $(4)$ & $(5)$ \\
\hline Reform Dummy & $\begin{array}{c}-3.671 * * * \\
(1.055)\end{array}$ & $\begin{array}{l}-1.017 \\
(1.401)\end{array}$ & $\begin{array}{l}-1.210 \\
(1.508)\end{array}$ & $\begin{array}{l}-1.207 \\
(1.471)\end{array}$ & $\begin{array}{c}1.572 \\
(1.341)\end{array}$ \\
\hline $\begin{array}{l}\text { Reform Dummy*Palm } \\
\text { Dummy }\end{array}$ & $\begin{array}{c}51.11 * * * \\
(6.955)\end{array}$ & $\begin{array}{c}36.58 * * * \\
(6.554)\end{array}$ & $\begin{array}{c}43.84 * * * \\
(7.015)\end{array}$ & $\begin{array}{c}38.69 * * * \\
(5.818)\end{array}$ & $\begin{array}{c}72.15 * * * \\
(7.025)\end{array}$ \\
\hline $\begin{array}{l}\text { Reform Dummy*Palm } \\
\text { Dummy* World Price }\end{array}$ & $\begin{array}{r}-0.564 * * * \\
(0.0937)\end{array}$ & $\begin{array}{c}-0.362 * * * \\
(0.0883)\end{array}$ & $\begin{array}{c}-0.437 * * * \\
(0.0932)\end{array}$ & $\begin{array}{r}-0.435 * * * \\
(0.0773)\end{array}$ & $\begin{array}{c}-0.816 * * * \\
(0.0965)\end{array}$ \\
\hline Reform Dummy*World Price & $\begin{array}{c}0.0336 * * \\
(0.0151)\end{array}$ & $\begin{array}{l}-0.0229 \\
(0.0160)\end{array}$ & $\begin{array}{l}0.0326^{*} \\
(0.0188)\end{array}$ & $\begin{array}{c}0.0371 * * \\
(0.0171)\end{array}$ & $\begin{array}{c}0.000366 \\
(0.0212)\end{array}$ \\
\hline Palm Dummy*World Price & $\begin{array}{l}0.644 * * * \\
(0.0779)\end{array}$ & $\begin{array}{l}0.442 * * * \\
(0.0726)\end{array}$ & $\begin{array}{l}0.475^{* * *} \\
(0.0652)\end{array}$ & $\begin{array}{l}0.466 * * * \\
(0.0515)\end{array}$ & $\begin{array}{c}0.694 * * * \\
(0.108)\end{array}$ \\
\hline World Price & $\begin{array}{l}0.140 * * \\
(0.0551)\end{array}$ & $\begin{array}{c}0.293 * * * \\
(0.0555)\end{array}$ & $\begin{array}{c}0.243 * * * \\
(0.0470)\end{array}$ & $\begin{array}{c}0.348 * * * \\
(0.0344)\end{array}$ & $\begin{array}{c}0.371 * * * \\
(0.0815)\end{array}$ \\
\hline Palm Dummy & $\begin{array}{c}2.489 \\
(3.362)\end{array}$ & $\begin{array}{c}9.760 * * * \\
(2.928)\end{array}$ & $\begin{array}{l}6.619 * * \\
(2.986)\end{array}$ & $\begin{array}{l}5.503 * * \\
(2.558)\end{array}$ & $\begin{array}{c}-15.12 * * * \\
(4.059)\end{array}$ \\
\hline Intercept & $\begin{array}{c}81.80 * * * \\
(15.05)\end{array}$ & $\begin{array}{c}68.82 * * * \\
(18.34)\end{array}$ & $\begin{array}{c}101.3 * * * \\
(15.59) \\
\end{array}$ & $\begin{array}{c}99.75 * * * \\
(16.88) \\
\end{array}$ & $\begin{array}{c}105.0 * * * \\
(16.38)\end{array}$ \\
\hline Observations & 1,258 & 1,252 & 1,084 & 1,076 & 1,391 \\
\hline Year and Quarter dummies & Yes & Yes & Yes & Yes & Yes \\
\hline Ramadan Dummies & Yes & Yes & Yes & Yes & Yes \\
\hline Lentil Dummy & Yes & Yes & Yes & Yes & Yes \\
\hline Proxies for Distribution Costs & Yes & Yes & Yes & Yes & Yes \\
\hline
\end{tabular}

Notes: (1) Reform dummy=1 if an observation is from after the date of the actual reform: June 21, 2011. (2) The 1year sample consists of the period from June 3, 2010 to October 4, 2012, and 2-year sample spans from May 31, 2009 to October 4, 2012, and both samples exclude the announcement phase (90 days) with the exception of Column 1. (3) The DiD Comparisons for Palm are Wheat and Lentil. World Price Includes Palm, Wheat and Lentil.

(4) Unit for Palm is Litre and for Wheat and Lentil is Kg. (5) Standard errors are in parentheses and corrected using Newey-West (1987) procedure for heteroskedasticity and autocorrelation, assuming AR (3) process. *** p<0.01, $* * \mathrm{p}<0.05, * \mathrm{p}<0.1$ 
Table 6: Effects of the Reform on Wholesale Palm Oil Prices: Short-run vs. Long-run (Dependent Variable: Wholesale Price)

\section{Effects of Policy Reform Over Time \\ $\mathrm{X}=6$-Month \\ $\mathrm{X}=9$-Month}

(1)

Effects during first X months
Reform Dummy $^{\mathrm{SR}}(\mathrm{D}=1$ for First X Months after June 21, 2011)
Reform Dummy
Reform Dummy ${ }^{\mathrm{SR}} *$ Palm Dummy
Reform Dummy ${ }^{\mathrm{SR} * \text { World Price }}$

$-4.271 * *$

(1.829)

$60.49 * * *$

(7.849)

$-0.663 * * *$

(0.108)

0.0254
(2)

$-1.522$

(1.621)

$60.55 * * *$

(5.847)

$-0.641 * * *$

(0.0829)

$-0.0241$

(0.0225)
(0.0236)

\section{Effects After First $X$ months}

Reform Dummy ${ }^{\mathrm{LR}}$ ( $\mathrm{D}=1$ for $\mathrm{X}$ months After June 21, 2011)

Reform Dummy ${ }^{\mathrm{LR}} *$ Palm Dummy

$-4.959$

$20.21 * *$

(10.10)

$-0.204$

(0.130)

0.0335

(0.0211)

$0.215 * * *$

(0.0572)

$0.564 * * *$

(0.0800)

4.311

(3.394)

$64.95 * * *$

(24.38)

1,090

Yes

Yes

Yes

World Price

Observations

Lentil Dummy

$-4.003^{*}$

(2.255)

$-10.29$

(12.02)

0.132

(0.153)

$0.0788 * * *$

(0.0200)

$0.210 * * *$

(0.0537)

$0.568^{* * *}$

(0.0763)

4.290

(3.297)

90.96***

(13.68)

1,090

Yes

Yes

Yes

Notes: (1) The estimates are from a specification that includes both reform dummy ${ }^{\mathrm{SR}}$ and reform dummy ${ }^{\mathrm{LR}}$ (2) The sample consists of the period from June 3, 2010 to October 4, 2012, but the announcement phase (90 days) is excluded. Observations for palm, wheat and lentil: Pre-reform: 399; Post reform: 691. (3) Unit for Palm is Litre and for Wheat and Lentil is Kg. (4) Proxies for distribution costs include diesel price and exchange rate. (5) Standard errors are in Parenthesis and are corrected using Newey-West (1987) procedure for heteroskedasticity and autocorrelation, assuming AR (3) process. (6) *** denotes significant at the 1 percent, and ** at the 10 percent level. 
Table 7: Effects of the Reform on Retail (Consumer) Palm Oil Prices (Dependent Variable: Retail Price)

\begin{tabular}{lcc}
\hline & Mean Effect & Short vs. Long term \\
\hline Reform Dummy & $(1)$ & $(2)$ \\
Reform Dummy*Palm Dummy & $-3.754 * * *$ & $(1.384)$ \\
Reform Dummy*Palm Dummy *World Price & $\mathbf{4 7 . 1 1 * * *}$ \\
& $\mathbf{( 6 . 2 3 1 )}$ \\
Reform*World price & $\mathbf{- 0 . 4 7 1 * * *}$ \\
& $\mathbf{( 0 . 0 8 5 0 )}$ \\
\end{tabular}

Effects during first 9 months

Reform Dummy $^{\text {SR }}\left(\mathrm{D}=1\right.$ for First 9 Months after June 21, 2011) - $\quad-3.838^{* *}$

(1.627)

Reform Dummy ${ }^{\mathrm{SR}} *$ Palm Dummy $\quad 60.07 * * *$

(4.905)

Reform Dummy ${ }^{\text {SR }} *$ Palm Dummy *World Price $\quad \mathbf{- 0 . 6 0 9 * * *}$

(0.0685)

Reform Dummy ${ }^{\mathrm{SR} * \text { World Price }} \quad-0.0388^{* *}$

$(0.0175)$

Effects After First 9 months

Reform Dummy $^{\mathrm{LR}}\left(\mathrm{D}=1\right.$ for 9 months After June 21, 2011) $\quad-5.134^{*}$

Reform Dummy ${ }^{\mathrm{LR} * \text { Palm Dummy }} \quad \mathbf{- 0 . 8 7 4}$

(10.74)

Reform Dummy ${ }^{\mathrm{LR} * \text { Palm Dummy *World Price }} \quad \mathbf{0 . 0 7 9 0}$

(0.139)

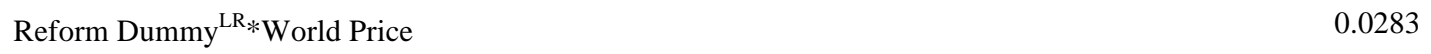

\begin{tabular}{lcc} 
& & $(0.0232)$ \\
\hline World Price*Palm Dummy & $0.618^{* * *}$ & $0.598^{* * *}$ \\
World Price & $(0.0751)$ & $(0.0670)$ \\
& $0.139 * *$ & $0.157 * * *$ \\
& $(0.0569)$ & $(0.0490)$ \\
\hline Palm Dummy & $5.445^{*}$ & $(2.766)$ \\
Intercept & $(2.946)$ & $61.31^{* * *}$ \\
& $67.71^{* * *}$ & $(9.631)$ \\
\hline Observations & $(12.09)$ & 1,090 \\
Full set of controls & 1,090 & Yes \\
\hline
\end{tabular}

Notes: (1) The estimates are from a specification that includes both reform dummy ${ }^{\mathrm{SR}}$ and reform dummy ${ }^{\mathrm{LR}}$. (2) The sample consists of the period from June 3, 2010 to October 4, 2012, but the announcement phase (90 days) is excluded. Observations for palm, wheat and lentil: Pre-reform: 399; Post reform: 691. (3) Unit for Palm is Litre and for Wheat and Lentil Kg. (4) Proxies for distribution costs include diesel price and exchange rate. (5) Standard errors are in Parenthesis and are corrected using Newey-West (1987) procedure for heteroskedasticity and autocorrelation, assuming AR (3) process. (6) *** denotes significant at the 1 percent, and $* *$ at the 10 percent level. 
Figure 1: World Market and Wholesale Prices of Palm oil

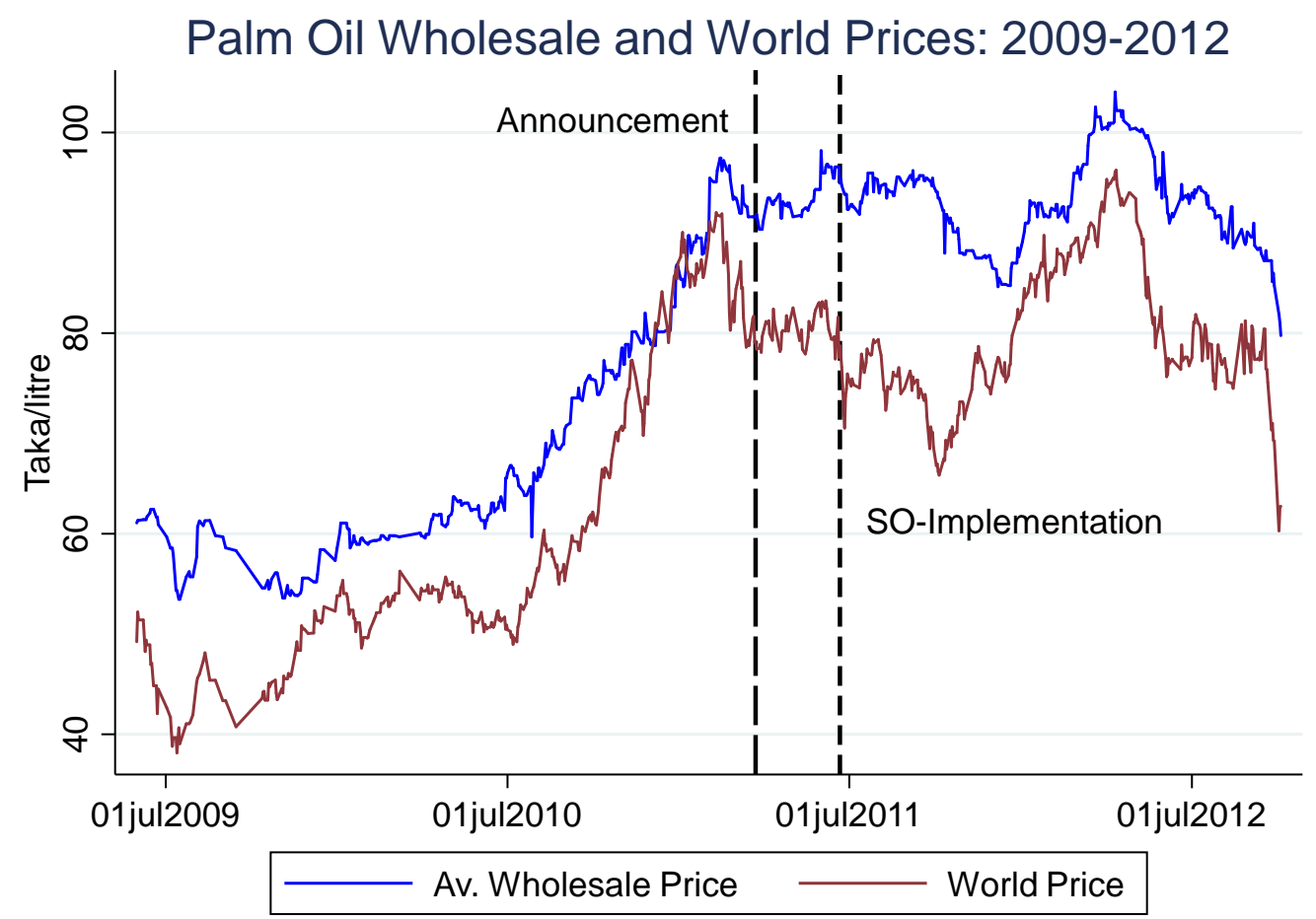

Figure 2: World-Wholesale Trading Margins: 4-Week lag in World Price

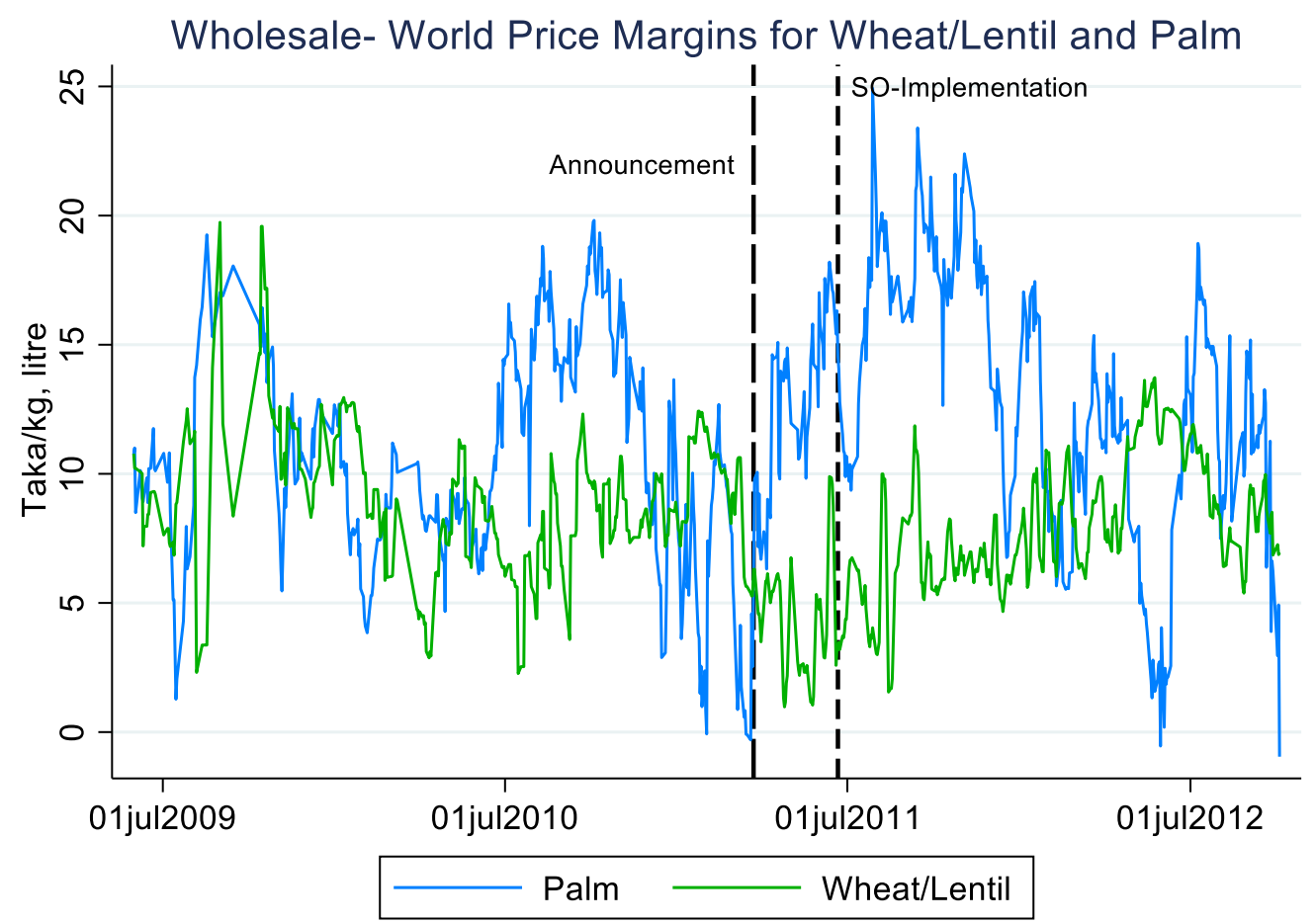


Figure 3: Test of Parallel Trends: Effects of Placebo Reforms on Passthrough in the Prereform Period

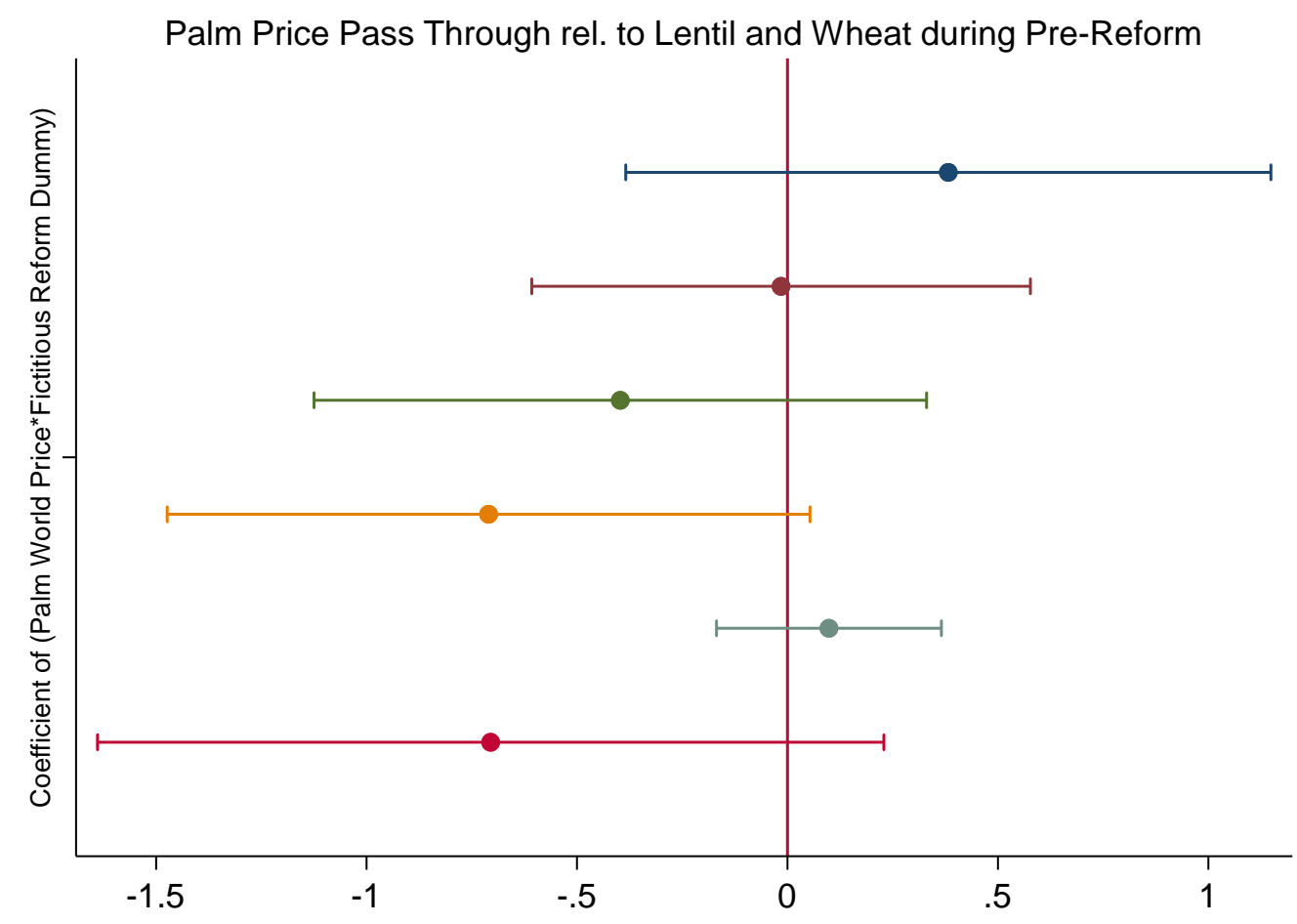

Notes: The sample used is 1 year before the announcement of the reform. We divide this pre-reform period into six different sub-periods: June 3, 2010 -July 14, 2010, July 15 2010-August 29 2010, August 30 2010-October 20 2010, October 21 2010-December 7 2010, December 8 2010-January 192011 and January 20 2011-March 212011. The placebo's are run so that $\mathrm{D}=1$ if the observations come from one of these sub-periods, and $\mathrm{D}=0$ otherwise. We test if a placebo reform affected one of these sub-periods and not the others. The six intervals present the 95\\% confidence intervals for the DiD estimate using wheat and lentil as comparison commodities. 
Figure 4: Palm Oil Import ('000 mt)

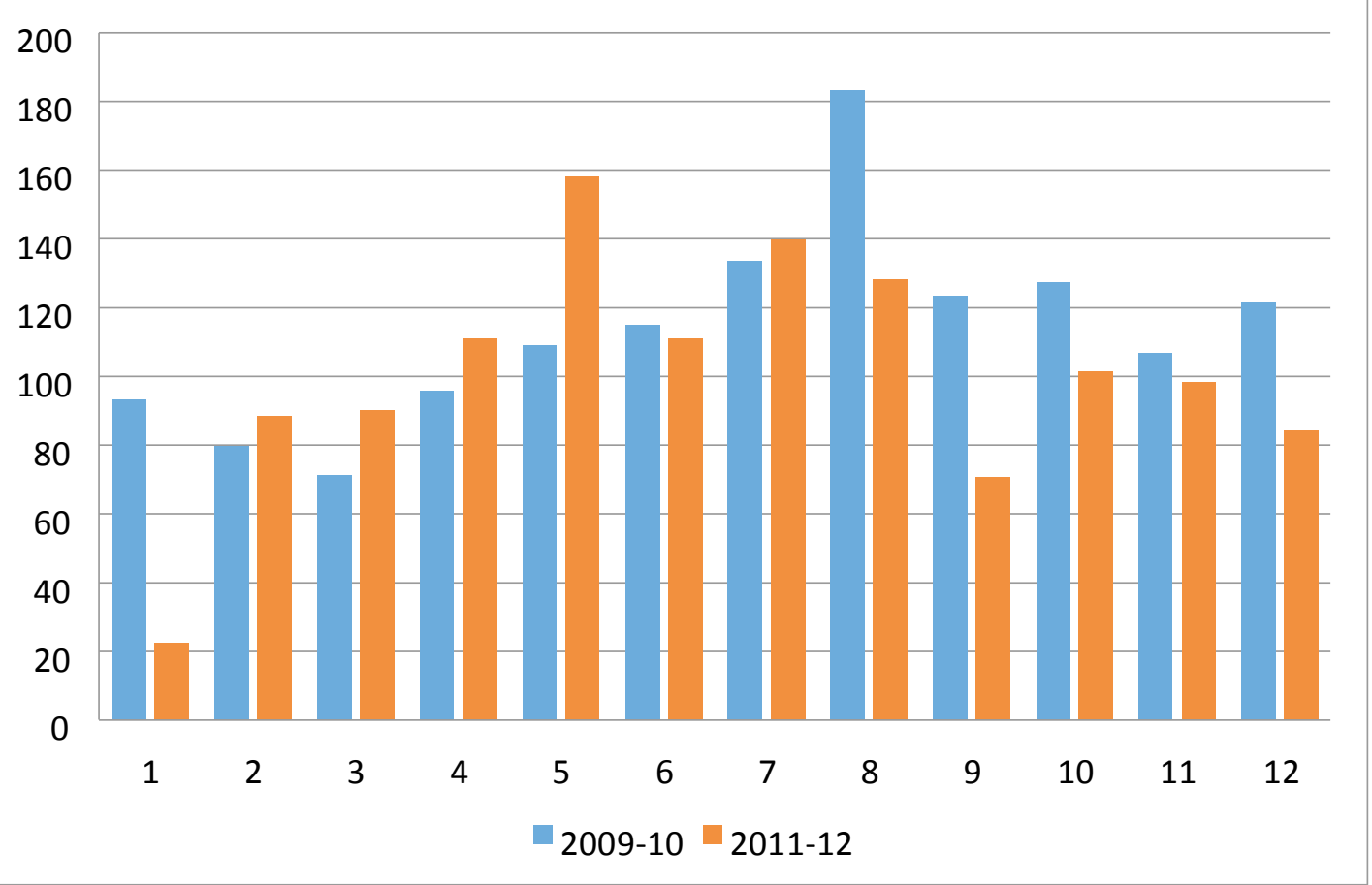

